\title{
On the Role of Cortical Area V4 in the Discrimination of Hue and Pattern in Macaque Monkeys
}

\author{
C. A. Heywood and A. Cowey \\ Department of Experimental Psychology, Oxford OX1 3UD, England
}

\begin{abstract}
Cortical visual area $\mathbf{V} \mathbf{4}$ in macaque monkeys has a large proportion of neurons that are sensitive to the wavelength or to the color of light. We tested its role in hue discrimination by removing it in macaque monkeys trained to discriminate small differences in hue. Hue discrimination thresholds were permanently elevated in 4 macaque monkeys in which V4 was removed bilaterally. In contrast, there was no impairment in achromatic intensity thresholds tested in an identical manner. However, the discrimination of pattern and orientation was also conspicuously impaired, indicating that area V4 is not concerned solely with processing information about wavelength. The multiple defect is consistent with evidence that V4 provides the major cortical visual input to the temporal lobe, where a large range of visual properties is registered.
\end{abstract}

The performance of monkeys with V4 ablation was compared with that of unoperated control monkeys and monkeys with removal of cortex in the banks and floor of the rostral superior temporal sulcus (STS). Removal of STS had only slight effects on pattern discrimination and none on hue discrimination. To control for the possible effects of inadvertent damage to the visual radiations when removing V4, the lateral striate cortex was partially ablated bilaterally in a control monkey. This had no effect on any discrimination, despite producing more retrograde damage to the lateral geniculate nuclei than in any monkey with $\mathbf{V} 4$ ablation. The visual disorder following removal of visual area V4 strikingly resembles the clinical disorder of mild cerebral achromatopsia with associated apperceptive agnosia for objects and patterns.

There is good anatomical and behavioral evidence for the existence of 2 distinct corticocortical pathways from the striate cortex in the macaque monkey (Ungerleider and Mishkin, 1982). The dorsal projection to the parietal lobe, implicated in visuospatial performance, has been contrasted with the ventral projection to the temporal lobe, which is crucial for object recognition. These 2 projections involve multiple visual areas in extrastriate cortex. Thus, the occipitotemporal projection, of major interest in the present experiment, involves the output of striate cortex to areas V2, V3, and MT (Cragg and Ainsworth,

\footnotetext{
Received Sept. 29, 1986; revised Dec. 23, 1986; accepted Feb. 27, 1987.

This research was supported by MRC Grant G971/397/B.

Correspondence should be addressed to Dr. C. A. Heywood, Department of Experimental Psychology, South Parks Road, Oxford OX1 3UD, U.K.

Copyright $\odot 1987$ Society for Neuroscience 0270-6474/87/092601-17\$02.00/0
}

1969; Zeki, 1969; Weller and Kaas, 1983; Ungerleider, 1985; Van Essen, 1985), the latter being associated with the dorsal pathway. The forward projections of V2 and V3 are to both MT and V4, and the latter provides the major input into the inferior temporal lobe (Zeki, 1971, Maunsell and Van Essen, 1983; Ungerleider, 1985; Van Essen, 1985).

One view of the role of the multiple visual areas in object recognition is that each area is relatively specialized for the analysis of a particular stimulus attribute, thus exploiting the potential for scrial and parallcl processing evident from their anatomical interconnectivity. Studies of patients with posterior cerebral lesions, where the resulting visual deficits appear to be confined to difficulties in the processing of a single psychophysical dimension such as color (see Meadows, 1974, for a review), or movement (Zihl et al., 1983), have added weight to the suggestion that a single visual area may subserve a relatively independent analysis of a specific visual attribute, probably at an early stage of visual processing. Consistent with this view, Zeki $(1973,1978 \mathrm{a}, \mathrm{b}, 1983 \mathrm{a}, \mathrm{b})$ has argued from the results of electrophysiological recordings from area V4 in the monkey that this area is specialized for the processing of both wavelength and color. Moreover, Zeki's results indicate that the responses of a large proportion of the cells show "color constancy," i.e., a cell will continue to respond to what a human observer perceives as a particular color of an object in a complex scene despite substantial variations in the wavelength composition of the incident light (Zeki, 1983a, b). Recently, a preliminary report suggests that removal of area V4 in the monkey leads to deficits in color constancy assessed behaviorally, without impairing hue discrimination (Wild et al., 1985). While an argument for the relatively independent analysis of a psychophysical dimension has been made in the case of V4, anatomical considerations cast doubt on it, not least because V4 provides the most substantial input into inferotemporal cortex and inferotemporal neurons respond to a variety of stimulus attributes other than color.

An alternative view (Desimone et al., 1985) is that the pathway into the temporal lobe is a serial hierarchy in which processing of different stimulus attributes may occur in parallel within one cortical area. The type of analysis then becomes more global at successive stages of processing. Recently, the spatial properties of the receptive fields of single neurons in V4 have been examined (Desimone et al., 1985). The degree of spatial selectivity of cells in V4 appears to be comparable with cells in $\mathrm{V} 1$, although showing some quantitative differences.

The present experiment was undertaken to establish the effects of removal of area V4 in the monkey on pattern and hue discrimination and so to determine the degree of independence between the processing of these different attributes. 


\section{Materials and Methods}

\section{Subjects}

Seven adult rhesus monkeys (Macaca mulatta) and 3 cynomolgus monkeys (Macaca fascicularis) were used. Two of the rhesus monkeys had previous expericnce of visual discriminations in an automatic testing apparatus. The remainder were experimentally naive.

Two series of experiments were carried out. First, animals were trained and preoperative measures were established. They were then assigned to 2 surgical groups and an unoperated control group, and postoperative measures of performance were established. Second, the 4 animals that served as unoperated controls subsequently received lesions that in 3 instances provided additional surgical controls. The fourth monkey became part of the main experimental group. For simplicity, the descriptions and results of these 2 experiments are reported separately.

\section{Surgery}

All surgery was carried out under an operating microscope using sterile procedures. Ablations were bilateral and made at a single operation. The animal was sedated with ketamine hydrochloride (Ketalar, ParkeDavis, $10 \mathrm{mg} / \mathrm{kg}$, i.m.), then deeply anesthetized with sodium thiopental i.v. (Pentothal, May and Baker) and placed in a headholder. After cutting and retracting the skin, fascia, and muscle, bone was then removed from above the intended area of ablation and the dura cut and reflected. Cortex was removed by subpial aspiration, using 20 to 22 gauge suckers. After all bleeding had ceased, the opening was closed in anatomical layers. A single i.m. injection of $360 \mathrm{mg}$. bicillin (Brocades, Ltd.) was given. All animals recovered promptly and uneventfully, and behavioral testing was resumed 3 weeks later.

In 3 animals (group V4) an attempt was made to remove the great majority of visual area $V 4$ as described by several investigators (see Ungerleider, 1985, for review). The whole of the exposed surface of the prelunate gyrus was removed from the inferior occipital sulcus ventrally to the junction of the intraparietal and lunate sulci dorsomedially. Anteriorly the removal extended into the lateral half of the inferior bank of the superior temporal sulcus, stopping short of the presumed border with visual area 5 (V5 or MT). Posteriorly it included the lateral half of the rostral bank of the lunate sulcus. Both banks of the most rostral $5 \mathrm{~mm}$ of the inferior occipital sulcus were removed. Ventral to the latter the ablation extended as far as the occipitotemporal sulcus on the ventrolateral surface of the brain but did not cross it, even though Ungerleider (1985) describes a fingerlike extension of V4 approaching the midline ventrally. As there are no sulci to mark its rostral and caudal boundaries we made no attempt to remove it.

In 3 animals comprising the operated control group (STS) the socalled face-cell area (Rolls, 1984) was removed, bilaterally in 1 animal and on one side in 2 others. In the latter, parts of the auditory association cortex were removed from the other hemisphere. The STS ablation included both banks of the sulcus for a length of about $20 \mathrm{~mm}$, starting approximately $5 \mathrm{~mm}$ in front of the tip of the inferior occipital sulcus. In addition, as much as possible of the floor of the sulcus within this region was removed where this could be done without damaging major vessels or encroaching on white matter that included the visual radiations. In the 2 animals with asymmetrical lesions a comparable ablation was made a few millimeters rostral and dorsal to the first one but in the sylvian sulcus of the opposite hemisphere. The STS ablation corresponds to or is even slightly larger than the area in which a substantial proportion of the neurons respond selectively to faces or to parts of them (see Rolls, 1984, for review).

The remaining 4 animals formed the unoperated control group. At the end of their behavioral testing as control animals, 2 received bilateral ablation of the banks and depths of the superior temporal sulcus as described above, and V4 was removed bilaterally in a third animal. The fourth animal was used to control for any advertent damage to visual radiations in the V4 group. Approximately one third of the lateral striate cortex was removed bilaterally, centered on the representation of the horizontal meridian from the foreal projection laterally to an eccentricity of about $5^{\circ}$ medially (Daniel and Whitteridge, 1961). By the time this control lesion was made the cortical lesions and thalamic degeneration in group V4 had been examincd. The control lesion in lateral striate cortex was accordingly designed to produce more severe but otherwise similar retrograde neuronal degeneration in the dorsal lateral geniculate nuclei as had been found in group V4. This animal was then tested for the third time on the range of visual discriminations.

\section{Histology}

At the end of the experiment each monkey was sedated and given a lethal dose of sodium pentobarbital i.v. before being perfused transcardially with $10 \%$ saline followed by formal-saline. The brain was blocked in the stereotactic frontal plane while still in the skull, then removed, photographed, and infiltrated with a solution of $30 \%$ sucrose in $10 \%$ formalin for at least 1 week. Frozen sections were cut in the frontal plane at $25 \mu \mathrm{m}$ and every $20 \mathrm{th}$ section stained with cresyl violet. Two additional 1 in 20 series through the area of the lesion and the thalamus were stained as before or for myelin by the method of Gallyas (1979). Retrograde degeneration in the thalamus was plotted by using a drawing tube attached to a microscope.

\section{Apparatus}

All testing was carried out in a Wisconsin General Testing Apparatus in the presence of masking white noise at about $65 \mathrm{~dB}$. The compartment in which stimuli were presented was $75 \mathrm{~cm}$ wide, $75 \mathrm{~cm}$ high, and 45 $\mathrm{cm}$ deep and lined with white matte cardboard. It was illuminated by 3 fluorescent lamps (Thorn, Artificial Daylight, color temperature $6500^{\circ} \mathrm{K}$.). Two lamps were placed vertically at the front of, and at each side of the compartment; the third was placed horizontally at the top. A fourth fluorescent lamp was placed directly above the animal's transport cage and in such a position that it cast only indirect light on the stimuli. These arrangements prevented shadows and highlights from appearing on the stimulus array when it was viewed from the animal's transport cage. Stimuli were presented to the animals on a matte-black Oroglass board $\left(56 \mathrm{~cm}\right.$ wide and $30 \mathrm{~cm}$ high), inclined at $30^{\circ}$ to the vertical with the top furthest from the animal. The stimulus plaques rested with their base on a narrow ledge and their top edge behind a horizontal black metal rod, and covered 2 food wells, $18 \mathrm{~cm}$ apart, which could be exposed only by displacing each stimulus laterally. The board on which the stimuli rested was mounted on a wheeled trolley. By means of a handle that projected through the 1-way vision screen at the rear of the compartment, the trolley could be pushed along fixed metal tracks towards the animal, which could then respond through the bars of the transport cage. Between trials an opaque screen was lowered between the animal and the display. The trolley was pushed forward 5 sec after the opaque screen was raised again.

For the initial 2-choice discriminations, 8 pairs of discriminanda were prepared. All discriminanda were mounted on $12.5 \times 12.5 \mathrm{~cm}$ white, Oroglass plaques. They were (1) a plain white plaque versus a black plaque with a $1 \mathrm{~cm}$ whitc border; (2) a plus sign with both the horizontal and vertical components of dimensions $1 \times 7.5 \mathrm{~cm}$ versus a square with each side again $1 \times 7.5 \mathrm{~cm}$; (3) a bright red plaque versus a dark green one, both with a $1 \mathrm{~cm}$ white border; (4) a 4-cycle vertical square wave grating where each bar was $1 \times 9 \mathrm{~cm}$ versus an identical but horizontal grating; and (5)-(8) four 2-choice monkey face discriminations. The stimuli were black-and-white photographs of monkey faces, 4 rhesus and 4 cynomolgus. Each was $9.5 \times 12.5 \mathrm{~cm}$ and mounted on the plaques described above. The photographs were covered with transparent Oroglass attached to the top and base of the plaques with $1 \mathrm{~cm}$ black slide binders.

For "color" discriminations, the stimuli were Munsell color swatches $(7.5 \times 5 \mathrm{~cm})$ mounted between sheets of nonreflective glass, held together at top and bottom with $1 \mathrm{~cm}$ black binders. The technical specifications of each series of stimuli, using the conventional notation, were as follows. For the "red" stimuli the value (="brightness") was 6 and the chroma (="saturation") was 12 , the hue ranged from $2.5 \mathrm{R}$ to $5 \mathrm{YR}$ in 1.25 hue steps, resulting in 11 stimuli in all. There were similarly 11 stimuli in each of the "green-yellow," the "blue" and the achromatic series of stimuli. The "green-yellow" stimuli were all of value 7 and chroma 12 , with the exception of $1.25 \mathrm{GY}$, where the value was 8 . The series ranged in hue from 10YR to $2.5 \mathrm{GY}$, again in hue steps of 1.25 . The blue series were all of value 6 , but the chroma was variable. Specifically, $10 \mathrm{G}, 7.5 \mathrm{BG}, 10 \mathrm{BG}$, and $2.5 \mathrm{~B}$ had a chroma of $8,5 \mathrm{BG}$ a chroma of 12 , and the remaining 6 stimuli a chroma of 10 . The hue ranged from 10G to $5 \mathrm{~PB}$ in steps of 2.5 . The series of achromatic "grays" ranged from a value of $2.5 /$ to $7.5 /$ in steps of 0.5 . The CIE equivalents as percentages relative to $\mathrm{MgO}$, ranged from 4.61 to $50.68 \%$. Finally, the series of 9 stimuli that differed only in saturation had a hue of $2.5 \mathrm{YR}$, a value of 6 , and ranged in chroma from 0 (achromatic) to 16 in steps of 2. In each series there were 2 examples of each stimulus, an obvious necessity for oddity discrimination. Figure 1 shows the position of the chromatic stimuli plotted onto the standard CIE diagram ac- 


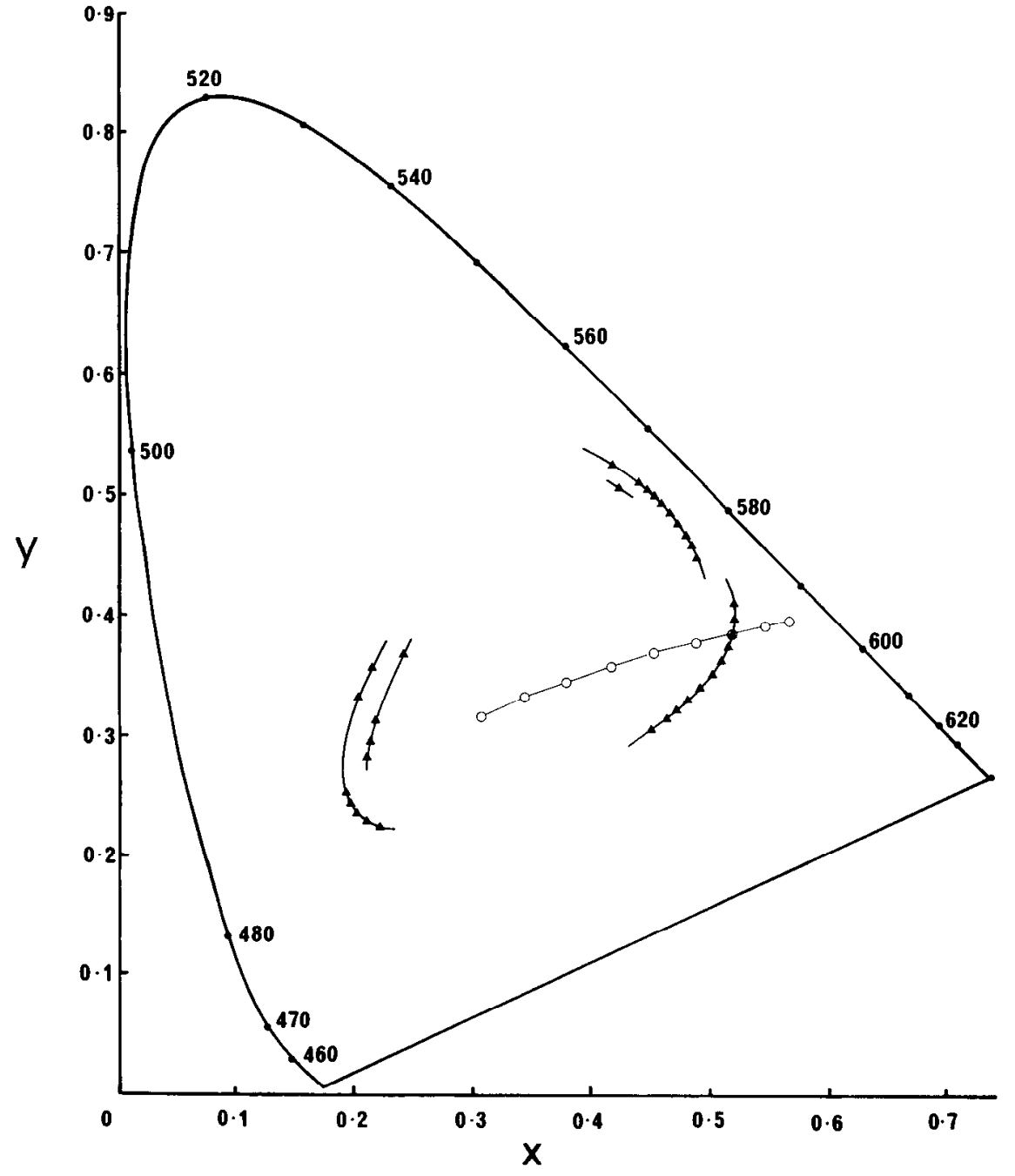

Figure 1. The CIE chromaticity diagram where the coordinates $(x, y)$ are plotted for each Munsell color sample for illuminant $\mathrm{C}$. The triangles represent the loci of the 3 series differing in hue and are connected by lines of constant chroma. The circles show the coordinates for the series differing in chroma (saturation) and are connected by a line of constant hue. cording to the data of Kelly et al. (1943), Granville et al. (1943), and Newhall et al. (1943). The slight variation in value or chroma in the green-yellow and blue series was caused by the commercial unavailability of certain stimuli.

\section{Procedure}

Monkeys were maintained in a healthy condition and received a diet of commercial chow, fruit, and vitamin supplements. They were fed shortly after testing and were therefore hungry when tested.

Two-choice visual discrimination. The animals were first trained on 2-choice visual discriminations. Prior to learning the first discrimination, they learned to take peanuts from an otherwise bare trolley. Both food wells were then baited and covered with identical gray plaques, and the animals rapidly learned to displace them. Finally, only 1 plaque was rewarded and correction trials and the buzzer were introduced. The intertrial interval was about $10 \mathrm{sec}$. For a typical trial, the opaque screen in front of the animal was raised, revealing the trolley and discriminanda. For $5 \mathrm{sec}$ the trolley remained out of reach of the animal. It was then pushed forward, allowing the animal to displace a plaque, and, if correct, to retrieve the peanut reward. The screen was then lowered. If the animal responded incorrectly, the screen was lowered immediately and a buzzer sounded for $2 \mathrm{sec}$. The experimenter was always concealed from the animal behind a one-way vision screen. Rerun correction trials were used, whereby following an erroneous response the spatial arrangement of the plaques on the subsequent trial was unchanged. When all animals were responding reliably, the discriminations described above were introduced. For each discrimination, the position of the rewarded plaque varied randomly, from right to left, with the constraint that no position was rewarded for more than 4 consecutive occasions. Animals received 50 trials per day and were tested 5 or 6 days a week. The preoperative criterion for learning each discrimination was 90 correct out of 100 consecutive trials. The number of errors made in reaching criterion was taken as the measure of performance.

"Oddity" discrimination. In an oddity discrimination the animal's task is to select the odd stimulus in 3 (or more) stimuli. In the present experiment 3 colors or 3 grays were presented. The animal had to displace the odd one and ignore the 2 identical ones. Such a task has the advantage that every stimulus is equally often positive and negative, and the animal cannot cheat by responding to artifacts such as scratches and marks; instead it must detect the stimulus that differs from the other 2 stimuli. However, as pointed out by French (1965), in many demonstrations of oddity learning animals may be responding on the basis of specific stimulus configurations rather than by learning and using the principle of oddity. For example, when 3 stimuli lie side by side, the odd one out, when at either end, may be perceived by an animal as smaller than the other 2 combined. Or the animal may compare stimuli 1 and 2 then 2 and 3 and detect the correct one by nonmatching. In the present experiment, where oddity performance for color samples was tested, the precisc mcans used to solve the discrimination cannot be established, and therefore use of the term "oddity" does not imply that the animal has learned to extract the principle of oddity (Robinson, 1933).

On each trial a row of 3 Munsell color swatches, edges $1 \mathrm{~cm}$ apart, was presented. The central swatch was immovable but the 2 flanking swatches could be displaced laterally to uncover the food wells. For "oddity" discrimination, 2 stimuli were identical and the third differed along the appropriate dimension of hue, reflectance, or saturation. The task of the animal was to choose the odd stimulus, which always appeared to the left or right of the central one. Restricting the position of 
the rewarded stimulus to the left or right, and never in the center of the stimulus array, was adopted to facilitate learning (Moon and Harlow, 1955). The discriminanda were presented in the same way as for 2-choice discrimination learning described above.

\section{Experiment 1}

The task was taught in stages.

Stage 1. The stimuli used for training were yellow and blue "art" papers matched neither for saturation nor reflectance. The monkey was presented with 2 blue stimuli and a yellow one, and was required to displace the yellow one for food reward. The "correct" stimulus was varied randomly to the right or left of the central one, and 64 trials were presented each day. When the monkey achieved 9 correct responses in 10 consecutive trials, the discrimination was reversed. Thus, 1 blue and 2 yellow stimuli were now presented, and displacement of the blue was rewarded. Reversals were carried out each time the monkey reached $9 / 10$ correct, until 10 reversals had been solved.

Stage 2. Animals were given 64 trials a day where both of the trial types described above were used in the session. Thus the configurations $\mathrm{YYB}^{+}, \mathrm{BBY}^{+}, \mathrm{B}^{+} \mathrm{YY}$, and $\mathrm{Y}^{+} \mathrm{BB}$ were presented in random order. Training was continued until $80 \%$ correct was achieved in a single session.

Stage 3 . This stage was identical to stage 2 except the red and green stimuli were used instead of blue and yellow. Training was again continued until $80 \%$ correct was achieved in a single session.

Stage 4. The stimuli were 4 pairs of Munsell color swatches. The Munsell notations were $2.5 \mathrm{R} / 6 / 12,5 \mathrm{~B} / 6 / 10,10 \mathrm{GY} / 6 / 12$, and $10 \mathrm{Y} / 7 /$ 12 , corresponding to a red, a blue, a green, and a yellow, respectively. An identical pair of one color could appear with a single example of any of the other colors, thus yielding 12 trial types. Animals received 72 trials a day until performance reached $80 \%$ correct or better in a single session.

Stage 5. This was identical to stage 4 except that the 4 pairs of discriminanda were $2.5 \mathrm{R} / 6 / 12,7.5 \mathrm{R} / 6 / 12,5 \mathrm{YR} / 6 / 12$, and $10 \mathrm{YR} / 6 / 12$. The hue difference between adjacent swatches on the Munsell scale was therefore reduced, thus increasing task difficulty.

Stage 6. Finally, animals were tested on the full range of 11 Munsell reds. Each block of 220 trials was made up of every possible unique combination of swatches. For each combination each swatch appeared once rewarded and once unrewarded, and within this condition once on the left and once on the right. Animals were given 55 trials a day. Since it was unclear what level of performance could be expected in this task, animals were tested until it became clear that some animals were reliably achieving $80 \%$ correct in a a single session. Testing was continued until animals reached a criterion of at least $80 \%$ correct over 440 trials. This was then taken as a measure of preoperative performance. Testing was then carried out using the green/yellow and blue ranges of Munsell papers. All animals readily transferred to the new hues, and it was then necessary to test over only 440 trials to establish measures of performance.

\section{Postoperative testing}

Testing resumed either 3 weeks after surgery or 3 weeks after the completion of preoperative testing for unoperated control animals. First, the eight 2-choice simultaneous visual discriminations were presented, in the same order as before. Testing continued at 50 trials a day, to a maximum of 1000 trials or until a criterion of 90 correct out of 100 consecutive trials was reached. The animals were then returned to stage 4 of the "oddity" discrimination, and the procedures described above were repeated until postoperative performance measures were established for each of the 3 ranges of hues. Animals then received several discriminations that were only given postoperatively, as follows.

a. 880 trials (55/day) were given in a manner identical to that described for the 3 hues, but the stimuli were now the series of 11 achromatic, "gray" Munsell swatches.

b. 220 trials (55/day) were then given, again as an "oddity" discrimination, on a retest of the blue range, to indicate the permanence of any postoperative change in performance.

c. 576 trials ( $72 /$ day) were given as an "oddity" discrimination using the 9 Munsell swatches that differed in chroma, i.e., saturation.

d. Animals received 288 trials (72/day) on the yellow/green range, again as an "oddity" discrimination. However, although the full range of 11 stimuli was used, the pairings of hue were such that the most difficult discrimination was never less than 3.75 Munsell hue steps, as compared with 1.25 hue steps in the previous measures of hue discrimination. It was then possible to see the effect of overall task difficulty on the performance at any particular difficulty of discrimination. In other words, animals may have consistently responded at $50 \%$ correct at the most difficult discrimination in the "oddity" set regardless of whether this was of 1.25 or 3.75 hue steps apart.

e. Animals were tested on a 2-choice simultaneous discriminaton of a pair of red swatches. The difficulty of the discrimination was chosen according to the postoperative performance of the group on the "oddity" discrimination of the red range, namely, $6.25 \mathrm{R} / 6 / 12$ versus $8.75 \mathrm{R} / 6 /$ 12 for STS and UNOP and $6.25 \mathrm{R} / 6 / 12$ versus $2.5 \mathrm{YR} / 6 / 12$ for group V4. In this, and in all subsequent 2-choice discriminations, animals received 50 trials a day until a criterion of 90 correct out of 100 consecutive trials was reached. If this was not achieved in 500 trials, testing was stopped. If criterion was reached, animals were transferred to an identical discrimination for 20 trials using fresh Munsell stimuli to ensure that animals were responding on the basis of the intended cue rather than minute scratches, etc.

f. Animals were required to discriminate between 2 achromatic gray swatches 0.5 steps apart in value, specifically $4.5 /$ versus $5.0 \%$.

g. Next, a discrimination between 2 swatches that differed by both 1 step in value and 1.25 steps in hue was taught, namely, $10 \mathrm{Y} / 7 / 12$ versus $1.25 \mathrm{GY} / 8 / 12$

h. The final discrimination was between 2 swatches differing only by 1.25 steps in hue, $6.25 \mathrm{Y} / 7 / 12$ versus $7.5 \mathrm{Y} / 7 / 12$. This was done to see whether extensive practice with a single pair of similar hues might allow animals to discriminate them.

\section{Results}

\section{Histology}

Figures 2 and 3 show drawings of surface reconstructions of the lesions, together with outlines of representative sections through the lesions and sections through the lateral geniculate nuclei and pulvinar nuclei.

In group V4 the dorsal parts of the lesions were largely as intended. The removals dorsal to the inferior occipital sulcus along the prelunate gyrus and into the lunate and superior temporal sulci were remarkably similar in the 4 animals. However, there were differences more ventrally that may be important. In V4-1 and -2 the lesion failed to reach the occipitotemporal sulcus on one or both sides. Furthermore, it did not encroach substantially into the area described as TEO (Bailey et al., 1950; Mishkin, 1972) just rostral and ventral to the anterior limb of the inferior occipital sulcus. In V4-2, where the lesion was smallest, the representation of the superior visual field was extensively spared. In contrast, area TEO was invaded by the lesion in V4-3 and -4. This difference is reflected in the extent of the retrograde degeneration in the pulvinar. In V4-1 and -2 the cell loss and gliosis were both less extensive and less conspicuous than in V4-3 and -4. In all 4 animals the degeneration was confined to the lateral pulvinar, cxccpt rostrally in V4-1 and 4-3, where it may have crossed the unclear boundary between lateral and inferior pulvinar. The retrograde degeneration in the 5 animals with lesions in STS was remarkably slight, and confined to the caudal third of the pulvinar nucleus, extending over a distance of less than $1 \mathrm{~mm}$. It was more medial and more caudal than in group V4 and greatest in STS-3 and -5 (Figs. 2, 3).

There was retrograde degeneration in the dorsal lateral geniculate nuclei of all 4 animals in group V4. It was most extensive in V4-3, where the majority of the neurons had degenerated in a band traversing the nucleus rostrocaudally on both sides. It was similar on the left in V4-1. On the right side in V4-1 and on both sides in V4-2 and -4 the degeneration was slight wherever it was discernible. In animal V1 the retrograde degeneration was both more extensive and more complete, although as in- 


\begin{tabular}{|c|c|c|c|c|c|c|c|c|}
\hline Animal & $\mathrm{B} / \mathrm{W}$ & $+/ \square$ & $\mathrm{R} / \mathrm{G}$ & $\mathrm{H} / \mathrm{V}$ & F1 & $\mathrm{F} 2$ & F3 & $\mathrm{F} 4$ \\
\hline \multicolumn{9}{|l|}{ Experiment 1} \\
\hline UNOP1 & 27,1 & 95,5 & 12,14 & 86,52 & 72,9 & 28,6 & 31,6 & 31,4 \\
\hline UNOP2 & 23,7 & 228,14 & 29,14 & 101,16 & 31,7 & 7,6 & 30,10 & 31,14 \\
\hline UNOP3 & 18,5 & 189,12 & 10,5 & 64,44 & 71,8 & 27,4 & 27,13 & 55,11 \\
\hline UNOP4 & 25,3 & 209,5 & 11,5 & 138,18 & 49,7 & 30,9 & 73,21 & 75,15 \\
\hline V4-1 & 9,0 & 312,64 & 5,2 & 72,62 & 92,76 & 35,9 & 50,50 & 68,25 \\
\hline V4-2 & 5,9 & 45,27 & 1,16 & 28,75 & 52,53 & 26,11 & 44,52 & 14,17 \\
\hline V4-3 & 25,6 & 88,197 & 1,15 & 55,116 & 44,200 & 15,124 & 48,119 & 38,200 \\
\hline STS1 & 24,14 & 216,7 & 2,6 & 16,29 & 18,23 & 9,4 & 4,11 & 31,3 \\
\hline STS2 & 18,2 & 213,13 & 6,9 & 64,11 & 13,50 & 21,10 & 15,16 & 27,8 \\
\hline STS3 & 8,2 & 58,15 & 7,4 & 23,60 & 41,41 & 20,6 & 20,18 & 18,5 \\
\hline \multicolumn{9}{|l|}{ Experiment 2} \\
\hline STS4 (UNOPI) & 2 & 9 & 6 & 4 & 5 & 4 & 4 & 10 \\
\hline STS5 (UNOP2) & 4 & 5 & 3 & 6 & 2 & 9 & 7 & 7 \\
\hline V1 (UNOP3) & 5 & 7 & 1 & 11 & 9 & 5 & 7 & 4 \\
\hline V4-4 (UNOP4) & 35 & 474 & 26 & 297 & 98 & $270 \mathrm{f}$ & 193 & $394 f$ \\
\hline
\end{tabular}

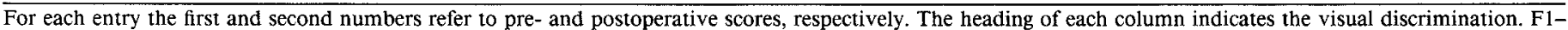

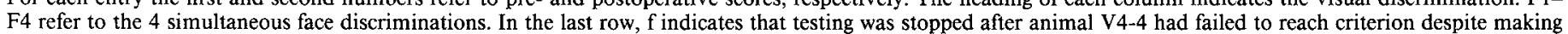
more errors than any other animal. B/W, black and white; $+/ \square$, plus/square; R/G, red-green; H/V, horizontal/vertical.

tended it involved a similar part of the geniculate nuclei as in group V4. The cortical lesion occupied chiefly the representation of the hortizontal retinal meridian on the lateral surface of the striate cortex (Talbot and Marshall, 1941; Daniel and Whitteridge, 1961). It extended to the central foveal representation on the left but fell short of it on the right. However, it extended more medially on the right and encroached on underlying striate cortex in the calcarine fissure. Not surprisingly the retrograde thalamic degeneration reached almost to the rostral tip of the lateral geniculate nucleus on this side. The visual field defect in this animal must have been sector shaped, extending from the fovea along the horizontal meridian in both directions. It would certainly be larger and denser than in any animal in group V4.

\section{Two-choice pattern discrimination}

Table 1 shows for each animal the number of crrors madc preand postoperatively in reaching the criterion of $90 \%$ correct, including the errors made in the 100 criterion trials. A savings score (difference between pre- and postoperative errors divided by their sum) was calculated for each animal for each of the 8 discrimination problems, and a mean rank determined for each animal. A Kruskal-Wallis one-way analysis of variance on the ranks showed that across all 8 problems there was a jusl-significant difference among the groups $(H=5.57, p=0.05)$. There was only a single overlap in the mean savings scores of the 4 unoperated animals and the 2 groups of operated animals. However the latter did not differ significantly from one another.

Table 1 clearly shows that there were no group differences in the unpatterned discriminations, i.e., black/white and bright $\mathrm{red} /$ dark green. A similar analysis was therefore carried out on the savings scores for errors for the 6 pattern discriminations ( 2 pairs of geometric forms and 4 pairs of photographs of faces). There was a significant difference among the groups $(H=6.66$, $p<0.02$ ), and once again Table 1 shows that this arises entirely from the superior performance of the 4 unoperated animals. There was overlap between the scores of the other 2 groups, which therefore did not differ significantly. Nevertheless, the 2 animals with poorest overall savings scores were both in group V4.

Even large differences in savings scores can be misleading when a discrimination is learned or relearned by several animals with very few errors (floor effects) because small differences in error scores lead to large differences in ratios. Table 1 shows that several patterns were mastered by several animals with very few errors. The groups were therefore additionally compared with respect to postoperative errors only, on the assumption that without any surgical intervention there would no group differences in retention. The animals were ranked with respect to total postoperative errors for each problem, and the mean rank across problems was determined as before. The difference among the groups was significant $(H=7.84, p<0.01)$, whether all problems werc included or only the 6 pattern discriminations. In each case, group V4 was impaired relative to group STS ( $\left.U=0, n_{1}=3, n_{2}=3, p=0.05\right)$ and to the unoperated group $\left(U=0, n_{1}=3, n_{2}=4, p=0.03\right)$. Group STS was not impaired relative to the unoperated group, either across pattern discriminations only ( $U=3, n_{1}=3, n_{2} ;=4, p=0.2$ ) or across all problems $(U=3, p=0.2)$.

Finally, Table 1 also shows the postoperative error scores for the previously unoperated animals that subsequently received STS or V4 ablation. Only the latter animal was impaired, and on all problems, confirming the differences reported above.

In summary, 4 animals with V4 lesions were impaired on 6 pattern discrimination problems, and 3 of them were also impaired on black/white and red/green discrimination. The monkeys with STS lesions showed mild but nonsignificant impairment compared with unoperated controls.

\section{Color discrimination}

Figure $4(a-k)$ shows pre- and postoperative performance for each group on each of the 3 ranges of chromatic stimuli, the achromatic series and the series differing in saturation. Each 

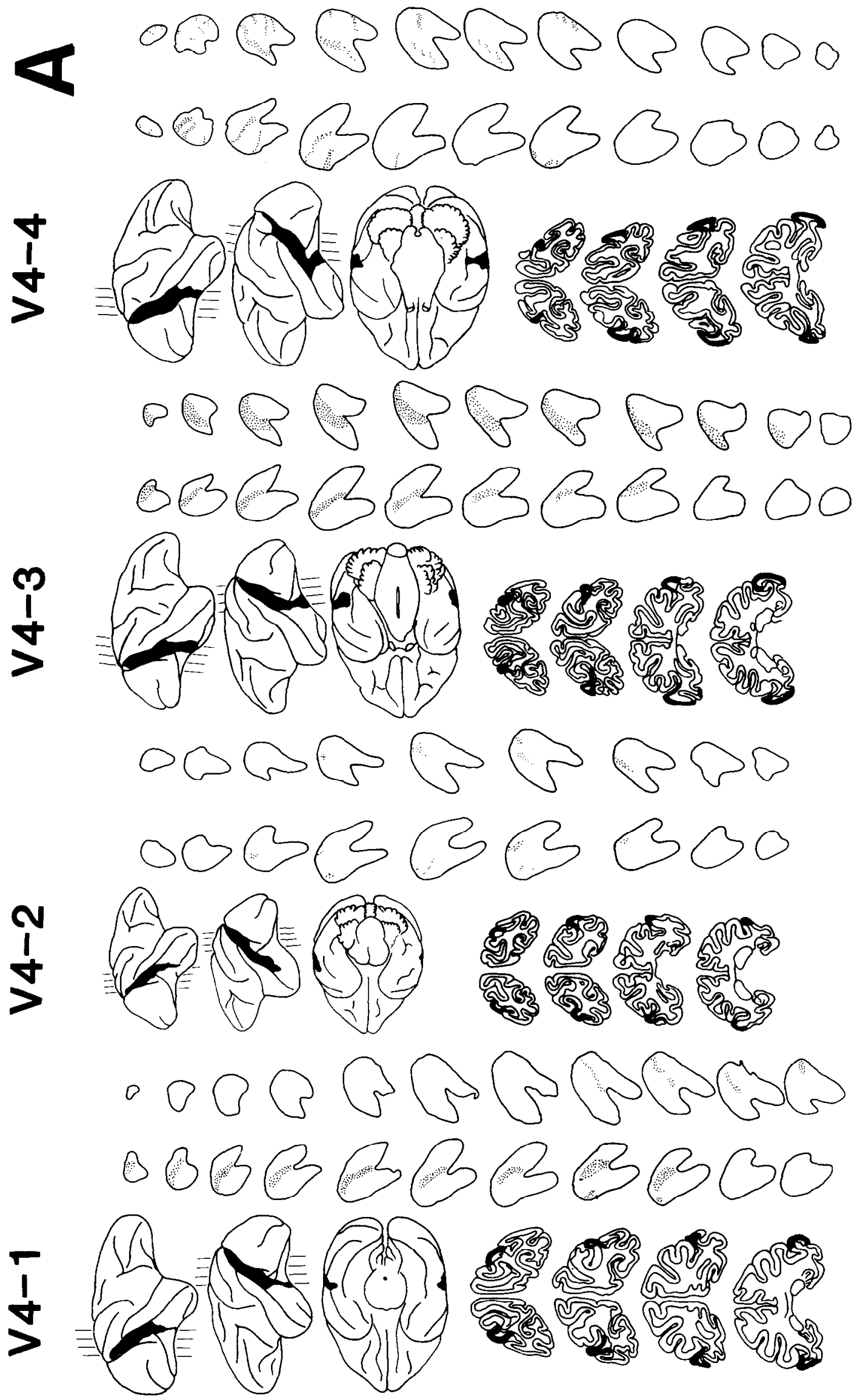


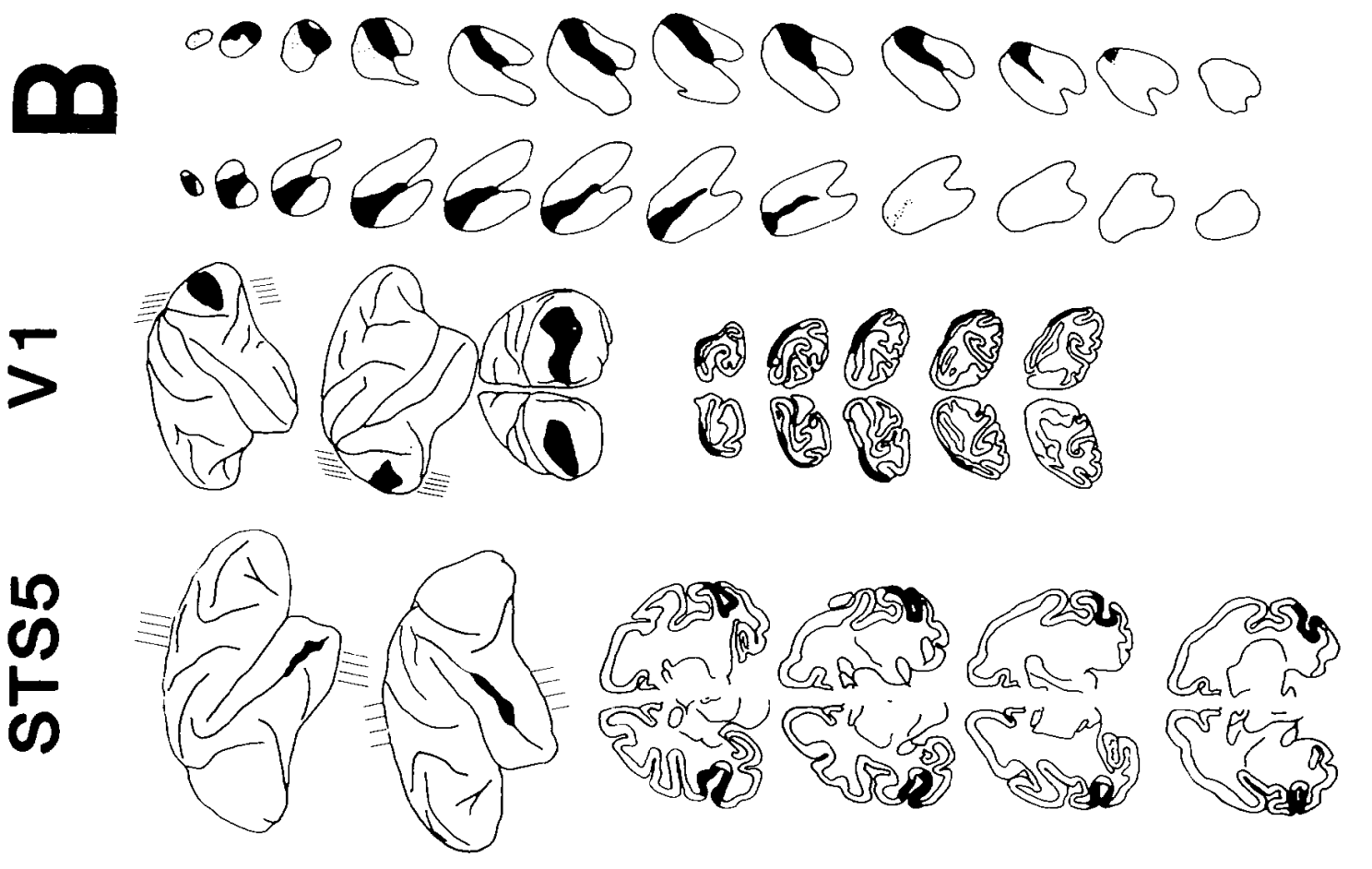

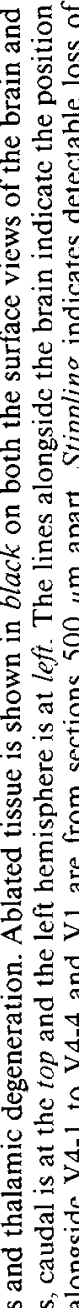

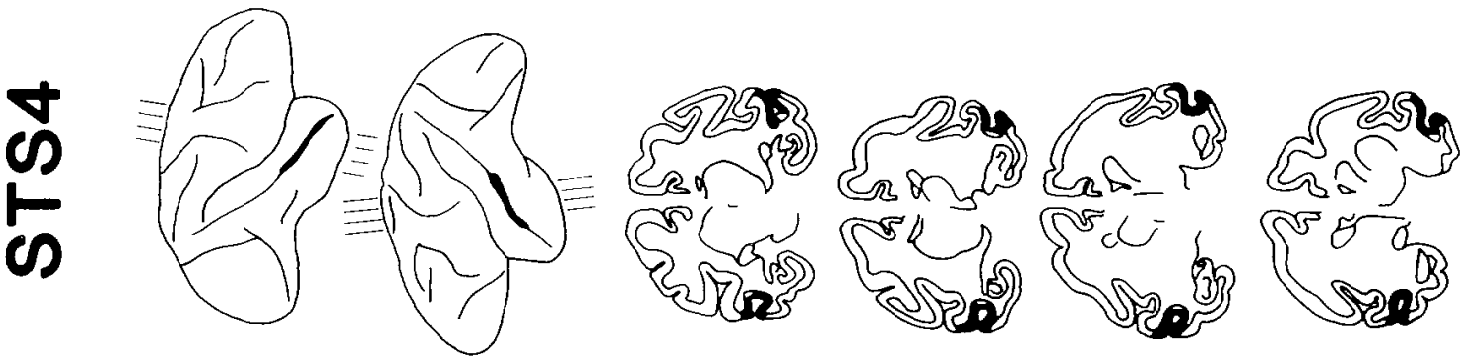

(2)

.

㣢

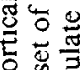

농

这焉

포

on

5

空

.

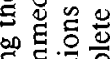

焉要

क力

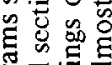

可 츨

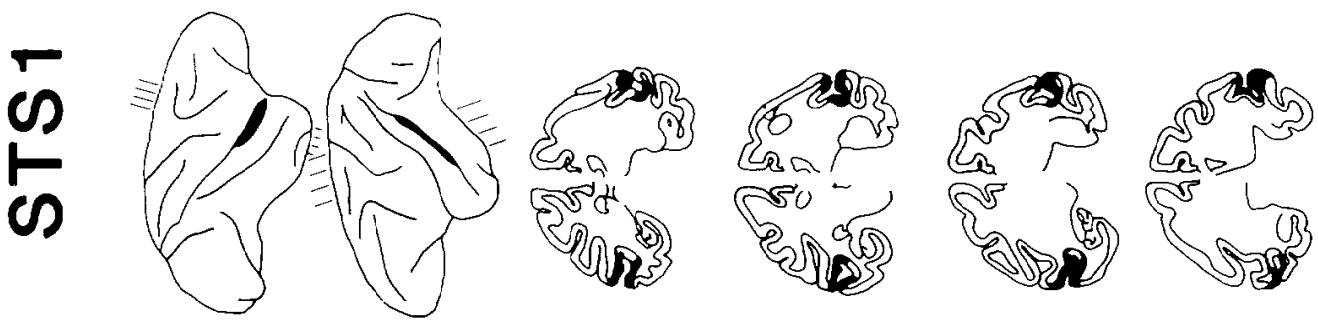

Q.

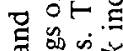

ד

i鸟密

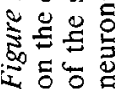




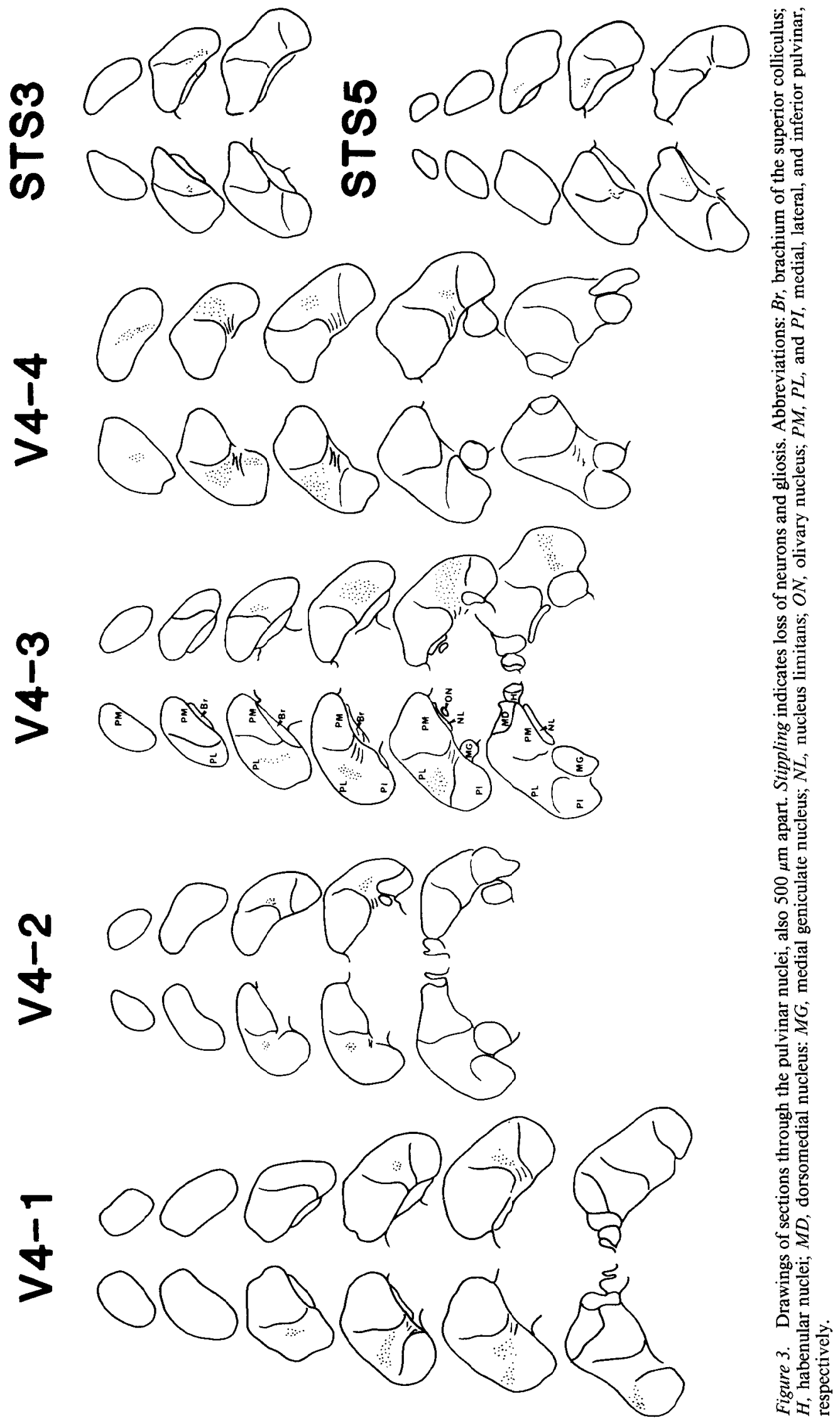


UNOP RED

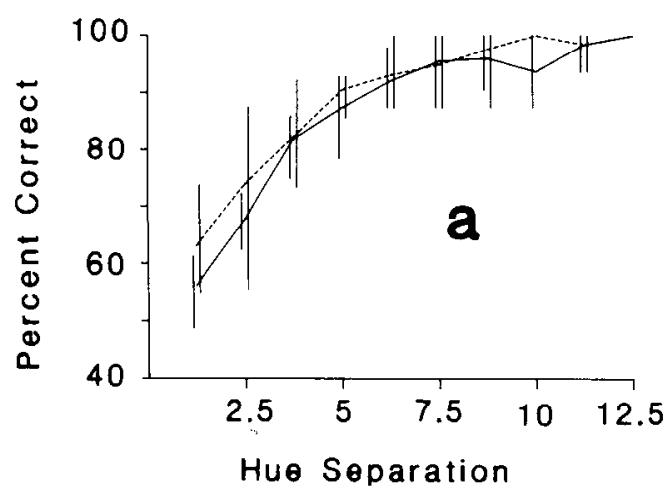

UNOP GREEN/YELLOW

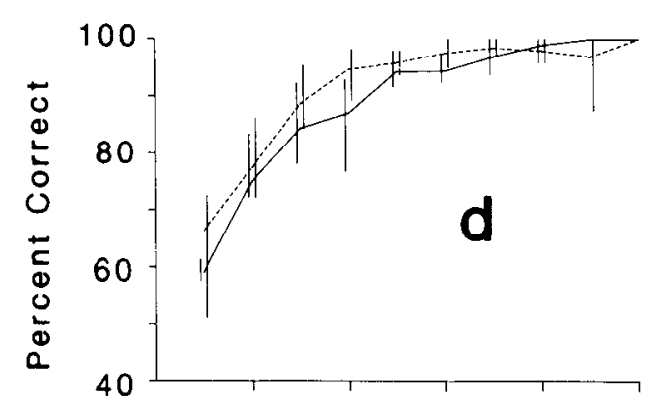

UNOP BLUE

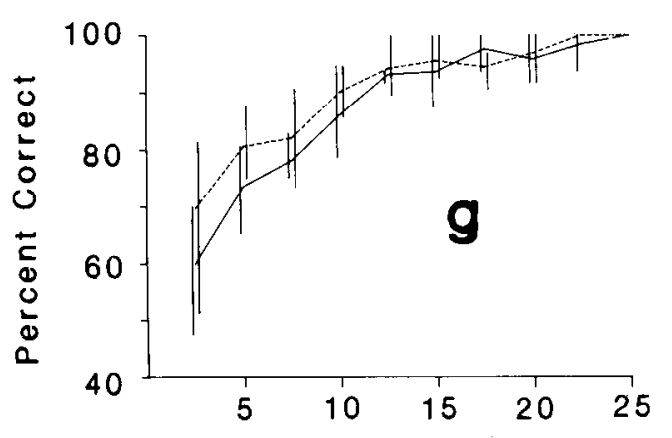

SATURATION

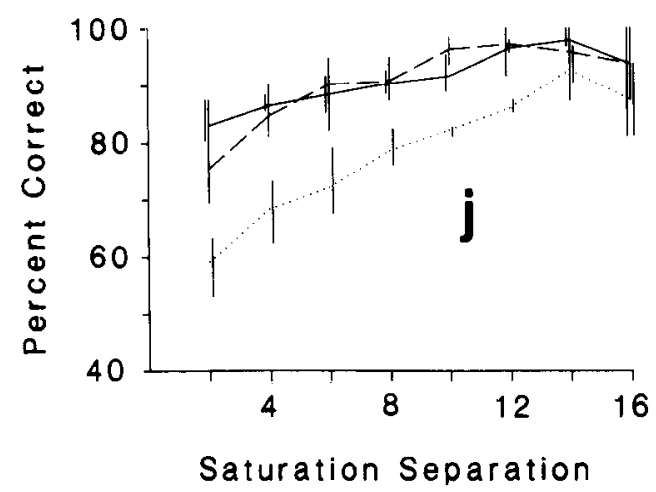

STS RED

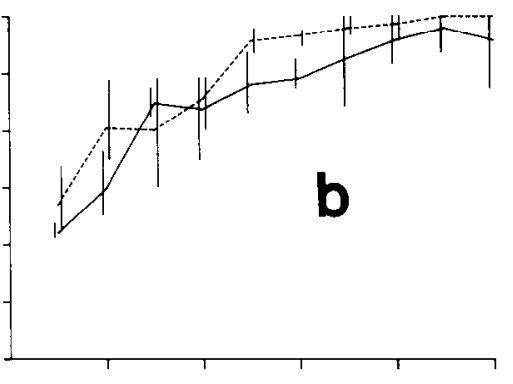

STS GREEN/YELLOW

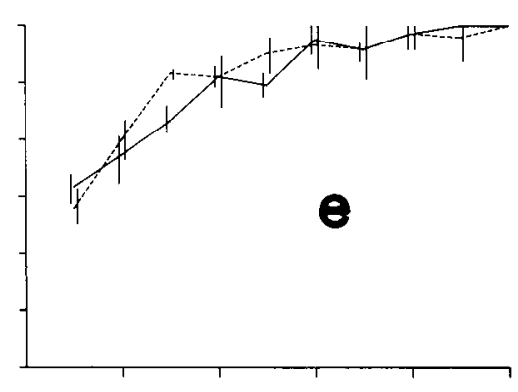

STS BLUE
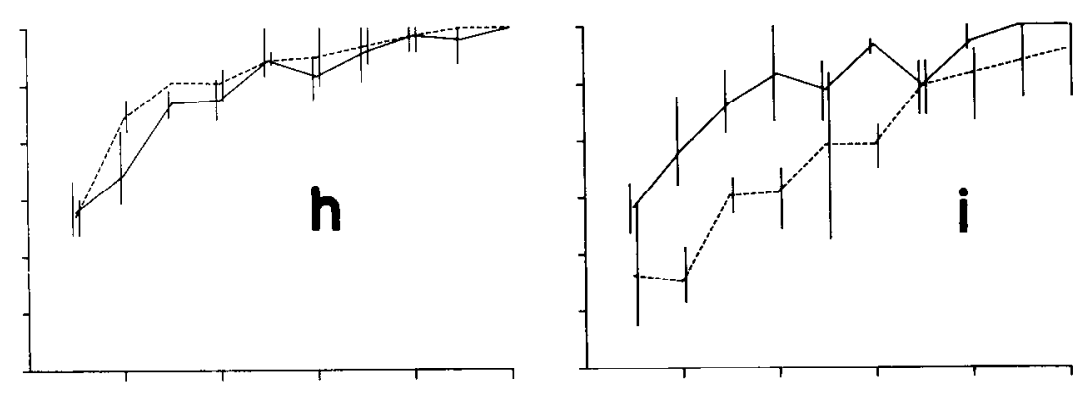

V4 GREEN/YELLOW

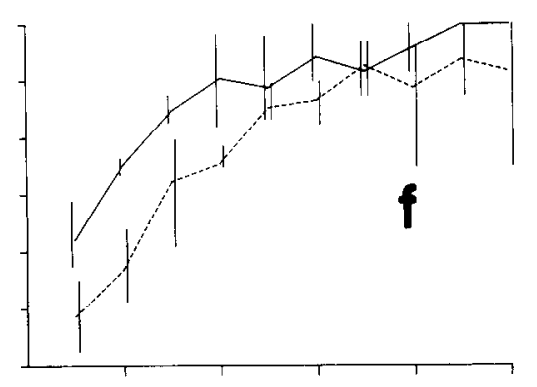

V4 BLUE
GREY

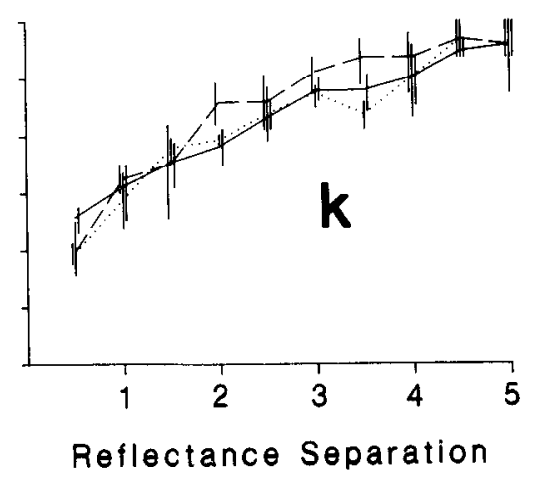

Figure 4. Each graph shows the mean percentage correct for the discrimination of each series of hues for each group. In each case the abscissa is in the appropriate Munsell units of hue, value, or chroma. $a-i$, Pre- and postoperative performances are shown by the solid and dashed lines, respectively. Vertical bars represent the range of scores contributing to each mean. $j$ and $k$, Mean postoperative performance for the discrimination of saturation and reflectance. Group UNOP is represented by the solid line and groups STS and V4 by the dashed and dotted lines, respectively. 


\begin{tabular}{|c|c|c|c|c|}
\hline Animal & $\begin{array}{l}\text { Red } \\
3^{-} \mathrm{v} 5^{+} \text {or } \\
3^{-} \mathrm{v} 8^{+}\end{array}$ & $\begin{array}{l}\text { Gray } \\
5^{-} \mathbf{v 6}^{+}\end{array}$ & $\begin{array}{l}\text { Green/ } \\
\text { yellow } \\
5^{-} \mathrm{v}^{+}\end{array}$ & $\begin{array}{l}\text { Green/ } \\
\text { yellow } \\
8^{-} 9^{+}\end{array}$ \\
\hline \multicolumn{5}{|l|}{ Experiment 1} \\
\hline UNOP1 & 8 & 13 & 10 & 11 \\
\hline UNOP2 & 7 & 13 & 8 & 8 \\
\hline UNOP3 & 7 & 11 & 11 & 8 \\
\hline STS1 & 12 & 69 & 5 & 13 \\
\hline STS2 & 4 & 14 & 7 & 5 \\
\hline STS3 & 8 & 27 & 12 & 16 \\
\hline V4-1 & 10 & 64 & $186 f$ & 16 \\
\hline $\mathrm{V} 4-2$ & 11 & 37 & $228 f$ & 32 \\
\hline V4-3 & 11 & 32 & $251 \mathrm{f}$ & 92 \\
\hline \multicolumn{5}{|l|}{ Experiment 2} \\
\hline STS4 (UNOP1) & 8 & 8 & 6 & 4 \\
\hline STS5 (UNOP2) & 6 & 5 & 5 & 4 \\
\hline V4-4 (INOP4) & 15 & 39 & $214 f$ & 110 \\
\hline
\end{tabular}

Note that for the red discrimination, the hue separation was 5 arbitrary steps for group V4 but only 2 steps for the other animals. ' $f$ ' indicates that an animal failed to reach criterion after 500 trials. The key below gives the Munsell description of the numbered hues; + and - indicate positive and negative stimuli, respectively. Key: Red 3, 6.25R/6/12; Red 5, 8.75R/6/12; Red 8, 2.5R/6/12; Gray 5, 4.5/; Gray 6, 5.0/; Green/yellow 5, 6.25Y/7/12; Green/yellow 6, 7.5Y/7/12; Green/ yellow $8,10 \mathrm{Y} / 7 / 12$; Green/yellow $9,1.25 \mathrm{GY} / 8 / 12$.

group mean for each stimulus separation is presented with a bar representing the full range of individual scores.

The data were analyzed using analyses of variance, with Groups, Lesion (pre- versus postoperative performance), and, in the case of the discrimination of hues, Color (i.e., the 3 ranges of chromatic stimuli) as Factors. Although it would be of interest to establish if a Group was only impaired on difficult discriminations by, for example, a raised threshold, difficulty of the discrimination (separation) was not used as a Factor for 3 reasons. First, as the number of trials decreased with increasing hue separation (see Materials and Methods), very few observations contributed to the mean for the easiest of the trial types. Second, there is a conspicuous ceiling effect, with all groups performing at close to $100 \%$ at wide separations of the discriminanda. Third, and most important, additional evidence showed that all groups were unimpaired on these easier discriminations from both postoperative retaining of stage 4 , described above, where, postoperatively, animals with V4 lesions achieved $80 \%$ correct, and the results of 2-choice color discriminations described below. The raw scores that were analyzed were therefore the total number of errors committed during each task.

The main effects of Groups $(F=44.19$, df $2,7, p<0.001)$, Lesion $(F=20.24, d f 1,7, p<0.01)$, and Color $(F=22.02, d f$ $2,14, p<0.001)$ were highly significant. The latter reflected the poorer performance for all groups on the red range, the first to be tested $(t=5.90, d f 14 ; t=6.68$, df $14 ; p<0.001$, for the comparison of the red range with the green/yellow and blue ranges, respectively). The interaction of Group by Lesion $(F=$ 126.28, df 2,7,p<0.001) demonstrates an impairment in the ability to discriminate hues following removal of cortical area V4, with no such loss in the operated control group $(t=14.45$, df $7 ; t=12.14$, df $7 ; p<0.01$, for each comparison between group V4 and the operated and unoperated control groups, respectively). In addition, both STS and unoperated groups were slightly better postoperatively $(t=3.31$, df $7 ; t=2.57$, df 7 ; $p>0.05$, for each respective comparison). Moreover, this interaction was not modified by Color $(F=0.26$, df $4,14, p>$ 0.2 ), indicating that the deficit was present with all 3 ranges of hue. The postoperative task of saturation discrimination presents a similar result. This analysis and the following analysis for the performance in the discrimination of achromatic stimuli exclude the data for UNOP-4, which is presented separately below, since this animal was tested on saturation and reflectance discrimination only after serving as an unoperated control and subsequently receiving a lesion to V4. As shown in Figure $4 j$, animals with V4 lesions showed a large impairment in the discrimination of saturation compared with either group STS or UNOP $(F=27.49$, df $2,6, p<0.01 ; t=8.69$, df $6 ; t=9.43$, df $6 ; p<0.01$, for each of the comparisons of V4 with group STS and UNOP, respectively), but these 2 latter groups did not significantly differ from each other $(t=0.74$, df $6, p>0.05)$. In striking contrast to this and the previously described performance on hues, a similar analysis conducted on the postoperative ability to discriminate between achromatic stimuli (see Fig. $4 k)$ yielded no group differences $(F=0.97$, df $2,6, p>$ $0.05)$.

All animals were retested on the blue range 7 month: after surgery to establish the stability of the impairment. The scores for the 220 trials under this condition were analyzed using oneway analysis of variance. There was an enduring impairment in the ability of animals with V4 lesions to discriminate hues $(F=20.40$, df 2,$6 ; p<0.01 ; \iota=8.29$, df $6 ; l=7.25$, df $6 ; p<$ 0.01 for the comparison of V4 with STS and UNOP, respectively). Groups STS and UNOP did not differ from each other $(t=1.03$, df $6, p>0.05)$.

Performance on the green/yellow range was tested under the condition where no discrimination was more than 3.75 Munsell steps apart. The number of errors made during the presentation of 288 trials were compared with the number of errors made for the same trial types when the full complement of trial types was used during postoperative testing of the yellow/green range but ignoring those trials less than 3.75 hue steps apart. In the analysis of variance, Groups and Conditions of testing (i.e., full versus incomplete range of stimulus separations in the concurrent tasks) were used as Factors. The main effect of Groups $(F=40.70$, df 2,$6 ; p<0.01)$ reveals that group V4 was significantly impaired relative to either of the other 2 groups $(t=$ 11.40 , df $6 ; t-10.64$, df $6 ; p<0.001$ for the comparisons of V4 with UNOP and STS, respectively). Groups UNOP and STS did not differ from one another $(t=0.76$, df $6, p>0.05)$. However, the absence of a significant effect of Conditions of testing $(F=2.74, d f 1,6, p>0.05)$ or the interaction with Groups $(F=0.39, d f 2,6, p>0.05)$ shows that for each group, discrimination for any particular hue separation was the same regardless of the total number of hues in the series and the separation of the most difficult of the discriminations in that range.

\section{Two-choice color discriminations}

Table 2 presents the number of errors made in reaching criterion on a variety of simultaneous 2-choice color discriminations, in each case including criterial trials. Mann-Whitney $U$ tests were used for group comparisons. Animal UNOP4 is not included in the comparisons since the data for this animal are presented 
below as an additional experimental animal, following the removal of V4.

The difficulty in discriminating reds was chosen for each group to be roughly matched on the basis of their performance on the oddity discrimination, i.e., 6.25 steps apart for the V4 group and 2.5 steps apart for all other animals. All groups learned with an approximately equivalent, and small, number of errors. For the discrimination of the achromatic gray stimuli 0.5 steps apart in value, it is apparent that although STS and V4 do not differ from each other $\left(n_{1}=n_{2}=3, U=3, p=0.35\right)$, both groups made more errors in reaching criterion than UNOP ( $n_{1}=n_{2}=3, U=0, p=0.05$, for each comparison). While the absolute error scores show this difference to be small, the ability to discriminate 2 stimuli 1.25 steps apart in hue presents a more striking group difference. All 3 animals with V4 lesions failed to reach criterion on the discrimination between 2 such yellow stimuli after 500 trials and failed to show substantial improvement, resulting in large error scores. The unoperated and operated control groups learned this discrimination with a small and similar number of errors $\left(n_{1}=n_{2}=3, U=3, p=0.35\right)$. Finally, when animals were required to discriminate between 2 stimuli that again differed in hue by 1.25 steps but, in addition, by 1 step in value (brightness), animals with V4 lesions showed a marked improvement in performance. Thus, while UNOP and STS were similar in their performance $\left(n_{1}=n_{2}=3, U=\right.$ $3, p=0.35)$ and V4 were impaired relative to $\operatorname{UNOP}\left(n_{1}=n_{2}=\right.$ 3, $U=0, p<0.05$ ), the difference between V4 and STS was slight and not statistically significant $\left(n_{1}=n_{2}=3, U=0.5\right.$, $0.1>p>0.05$ ), largely because of the small number of errors made by V4-1. When trials instead of errors to criterion are analyzed to remove the effect of the tied score, the difference still failed to reach significance $\left(n_{1}=n_{2}=3, U=1, p=0.1\right)$. By way of comparison, the performance of animals with V4 lesions on the latter discrimination was indistinguishable from their performance on discrimination of achromatic stimuli $\left(n_{1}=n_{2}=3, U=3.5,0.5<p<0.35\right)$.

\section{Experiment 2}

\section{Surgery}

At the end of the first experiment, those animals that had served as unoperated controls underwent surgery as follows. The cynomolgus monkey (UNOP3) received a partial bilateral lesion to the lateral striate cortex and is subsequently referred to as animal V1. Two of the rhesus monkeys (UNOP1, UNOP2) received bilateral lesions to the fundus of the STS and the third (UNOP4) sustained bilateral removal of area V4. These animals are hereafter referred to as STS4, STS5, and V4-4, respectively. Testing was then resumed.

\section{Postoperative testing}

All 4 animals were returned to the series of discriminations described in the postoperative testing in the previous stage, beginning with the eight 2 -choice discriminations, and testing was continued in a similar fashion for these subsequent tasks. However, animals were tested on a reduced number of tasks, in some cases with fewer trials. The sequence of tasks was as follows:

1. The eight 2-choice discriminations described previously were tested in an identical fashion.

2. Animal V1 was tested only on the red range for discrimination of color oddity; the remaining 3 animals were also tested on yellow/greens and blues.
V 1 RED

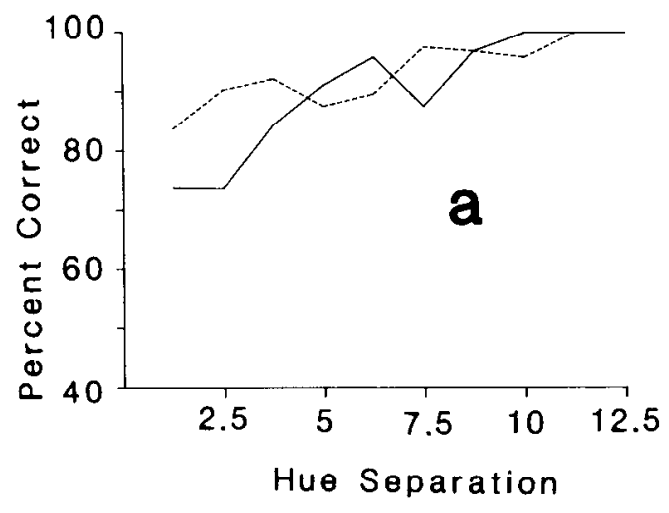

V1 GREY

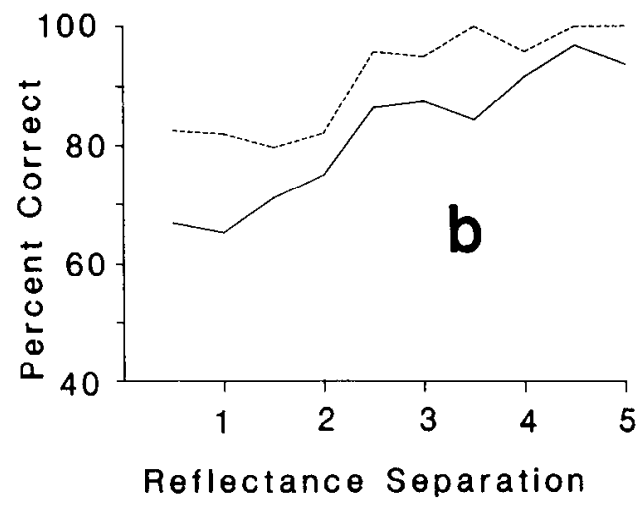

V1 SATURATION

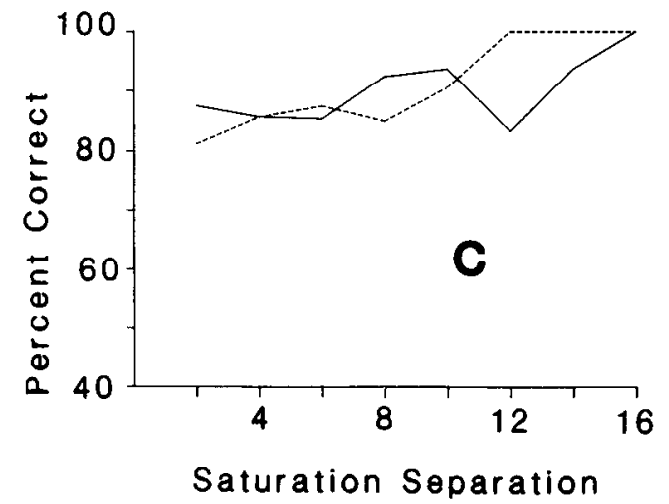

Figure 5. The 3 graphs $(a-c)$ show the pre- and postoperative performance on the red, gray, and saturation series for a single animal that served as an operated control and subsequently received a lateral striate lesion. Pre- and postoperative performances are shown by the solid and dashed lines respectively.

3. The series of achromatic grays.

4. The series that differed in saturation.

5. All animals, with the exception of $\mathrm{V} 1$, were tested on the four 2-choice simultaneous visual discriminations of color as in the previous stage.

Results for the 4 animals that served as unoperated controls and subsequently underwent surgery are considered below. In each case the percentage correct scored on each task is compared 
with the percentage correct scored on the task preoperatively. Where the number of trials is fewer, the performance is compared with the performance on an equivalent number of trials at their last presentation. In addition, the scores are compared where appropriate, with the scores of animals in the same experimental group.

Animal V1. This animal received a lateral striate lesion as a control for unintended damage to the underlying optic radiations in group V4. Any such damage may possibly have resulted in impairments of hue discrimination as a consequence of a central visual field defect rather than as a consequence of the removal of area V4 per se.

There was clearly no impairment in the retention of any of the 2-choice discriminations (Table 1). In each case the error scores are small and are comparable with those made in retention when serving as an unoperated control. Figure $5 a$ shows the pcrformance on the red range before and after removal of lateral striate cortex. The postoperative score of $90.9 \%$ is better than that of $85.7 \%$ scored on the previous, preoperative exposure to the task, when the normal range was $82.3-86.8 \%$. A similar result emerges for the discrimination of the gray range (Fig. $5 b$ ), for which the overall score of $87.7 \%$ is an improvement on the $81.1 \%$ scored on the previous exposure (range for the unoperated controls, 81.1-83.6\%). Finally, performance on saturation discrimination (Fig. $5 c$ ) was indistinguishable from the preoperative performance. The score of $87.8 \%$ is close to the preoperative score of $88.5 \%$ and close to the range of scores of the unoperated controls (88.5-90.3\%). The partial removal of lateral striate cortex failed to result in an impairment of hue, reflectance, or saturation discrimination.

Animal V4-4. This animal, previously UNOP4, received bilateral removal of area V4 to extend the findings reported above. Table 1 presents the errors to critcrion for the cight 2-choice simultaneous visual discriminations. When compared with the retention scores during experiment 1 , V4-4 showed substantial negative savings that, in each case, were greater than those shown by other animals in the V4 group, which were also grossly impaired in pattern discrimination.

Figure $6, a-c$, presents the performance of V4-4 on the three ranges of hue and includes the scores of the animal's second exposure to the task during experiment 1 for comparison. The postoperative scores of $67.3,75.0$, and $65.4 \%$ for the red, blue, and green/yellow ranges are similar to the scores of the other 3 animals in group V4. The ranges of scores for these latter animals were $61.8-69.8 \%, 69.3-74.1 \%$ and $71.6-72.5 \%$ for the 3 ranges of colors, respectively. The preoperative scores for V4-4, were $80.7,83.2$, and $83.6 \%$ for these same ranges.

For the discrimination of grays (Fig. $6 d$ ), where the groups did not differ in experiment 1, V4-4 made only 108 errors, i.e., fewer than any of the other 9 animals, whose range was 162214. Animal V4-4, though showing a large impairment in the discrimination of hues, was unimpaired in the discrimination of reflectance.

Finally, the overall score of $77.4 \%$ correct for discrimination of saturation (Fig. $6 e$ ) is greater than other animals in group V4 (range $72.2-73.9 \%$ ) but still well outside the range for groups UNOP and STS (ranges, $87.1-91.3 \%$ and $83.1-91.8 \%$, respectively). Animal V4-4 was therefore shown to be impaired on the discrimination of saturation.

The 2-choice discrimination of hues and grays confirmed the above findings. The discrimination of 2 reds 6.25 steps apart was achieved with 15 errors, comparable with the scores of the other 3 animals of V4. However, the discrimination of 2 yellows 1.25 steps apart, as with other animals in group V4, was failed after 500 trials. In contrast, the discrimination of 2 grays 0.5 steps apart was achieved in with 39 errors, which was within the ranges of both group STS and V4 (14-69 and 32-64, respectively). Finally, when 2 yellow stimuli differed by 1.25 steps of hue and, in addition, 1 step in value, the discrimination was achieved with 110 errors.

Animals STS4 and STS5. Animals UNOP1 and UNOP2 received bilateral lesions of the STS and are referred to as STS4 and STS5, respectively, in Tables 1 and 2. From Table 1 it is clear that neither animal was impaired in any of the eight 2-choice simultaneous visual discriminations. Error scores to criterion were small in every case and were comparable to the retention scores for the same discriminations presented in experiment 1 .

The overall percentage correct for the oddity discrimination in the red, blue, and green/yellow ranges (Fig. $5, f-h$ ) were 89.1, 92.0, and 90.2\% for STS4 and 91.1, 90.2, and 91.8\% for STS5. These are slightly better than the scores on the same tasks presented on the second occasion in experiment 1 . These were 82.3 , 86.4 , and $86.6 \%$ for STS4 and 86.8, 90.0, and 90.2\% for STS5. There was no evidence that the removal of cortex within the superior temporal sulcus disturbed discrimination of hues, and this was confirmed in the 2-choice hue discriminations, where all tasks were learned with very few errors (Table 2). A similar result emerged for the oddity discrimination of grays (Fig. 6i), where STS4 and STS5 scored 90.2 and $88.2 \%$, respectively. These scores are again slightly better than when the task was presented to the same animals in experiment 1 , where the scores were 82.0 and $83.6 \%$. The absence of an impairment in the discrimination of grays is confirmed by the small number of errors made for the discrimination betwecn 2 grays 0.5 stcps apart (Table 2). Finally, these 2 animals were unimpaired on saturation discrimination (Fig. $5 j$ ). The postoperative scores of 91.7 and $90.6 \%$ for STS4 and STS5 are almost identical with the scores of 89.2 and $90.3 \%$ made during experiment 1 . There was no evidence, therefore, that lesions of STS resulted in impairments of hue, reflectance, or saturation.

\section{Discussion}

Our principal findings are that bilateral removal of the major portions of cortical visual area V4 impairs pattern discrimination and thresholds for discriminating hue and saturation, without affecting thresholds for the discrimination of reflectance. Before considering how these results are related to the properties of cells in V4 and to disorders of color perception in human patients with occipitotemporal brain damage, it is necessary to discuss the nature and specificity of the defect itself.

Group V4 was impaired on every form of discrimination except reflectance (their sparing on the original red/green discrimination could reflect "floor" effects or the fact that the 2 colors were not matched for apparent brightness, or both). It might therefore be argued that their threshold elevation on hue and saturation discrimination reflected a pervasive visual learning or relearning defect that prevented them from performing as well as the other groups within the, albeit large, number of trials presented and that with protracted testing their thresholds would have been indistinguishable from those of the other groups and from their own preoperative thresholds. This proposal has been advanced before to explain examples of apparent threshold increments following inferior temporal cortical damage in mon- 
V 4-4 RED

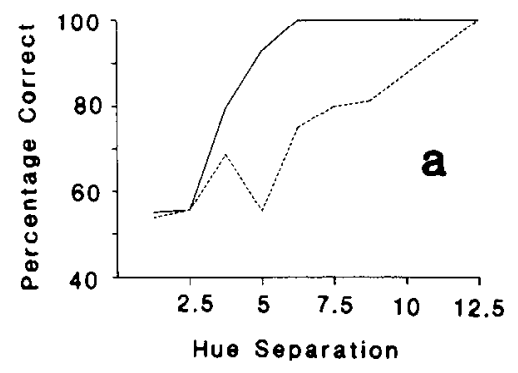

V4-4 GREEN/YELLOW

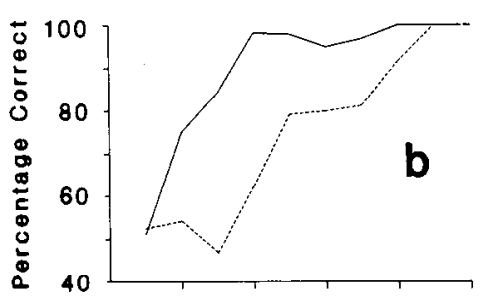

V4-4 BLUE

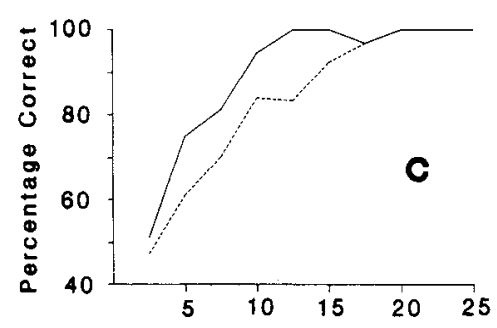

V4-4 GREY

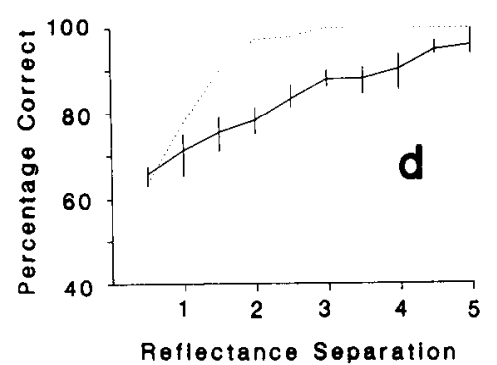

V4-4 SATURATION

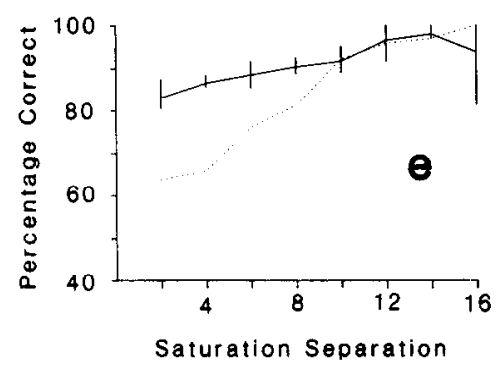

STS4 and STS5 RED

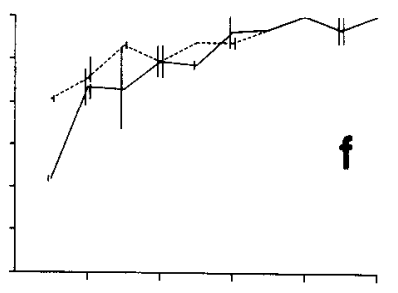

STS4 and STS5 GREEN/YELLOW

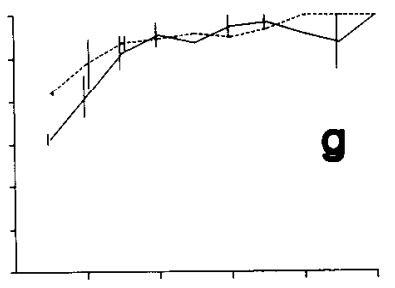

STS4 and STS5 BLUE

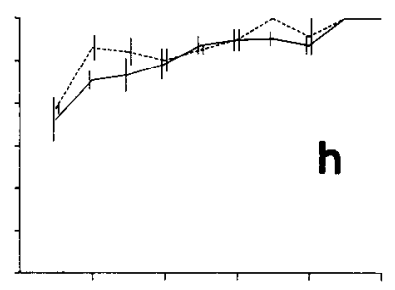

STS4 and STS5 GREY

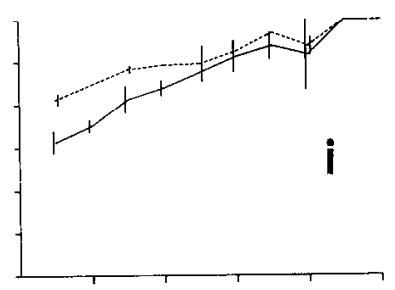

STS4 and STS5 SATURATION

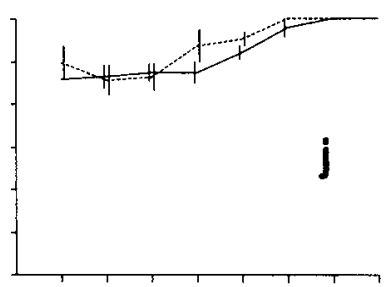

Figure 6. Graphs $a-c$ show the preand postoperative performance on hue discrimination of an animal that served as an unoperated control before receiving a lesion to area V4. Pre- and postoperative performances are shown by the solid and dashed lines, respectively. Graphs $d-e$ show the performance of V4-4 on reflectance and saturation (dotted lines) compared with the performance of the UNOP group (solid line). Vertical bars show the range of scores contributing to each mean. Graphs $f-h$ show the preoperative (solid lines) and postoperative (dashed lines) performance of the 2 animals that received lesions to the superior temporal sulcus after serving as unoperated controls. Graphs $i-j$ show the performance of the same 2 animals on the discrimination of reflectance and saturation. The solid line represents the preoperative performance of these 2 animals and can be compared with their postoperative performance (dashed line). keys (Dean, 1979), and the possibility is both plausible and difficult to eliminate. However, there are several reasons why it is unlikely. First, group V4 was not inferior to the others when tested in identical fashion with a series of grays that were more difficult than the hues for the other animals. This was the case even though the dimensional scales of hue and reflectance were selected to be similar as judged by human observers (Bellamy and Newhall, 1942). Although the grays were not presented preoperatively in experiment 1 and the comparisons are therefore between, rather than within, groups, this was also true of 
the series in which saturation of a single hue was varied. Here group V4 was impaired. Second, the result of retesting with one range of hues several months later showed that no improvement occurred. Third, testing with the same number of hues but reducing the minimum hue separation did not improve performance at any particular hue separation, indicating the defect was not a consequence of having to deal with too great a range of hue differences in each testing session. Fourth, the result of simultaneous visual discrimination with a single pair of hues (Table 2) makes the same point. There is therefore no compelling reason to reject the conclusion that group V4 had genuine difficulty in perceiving small differences in hue and in saturation.

Is the defect in hue discrimination more or less severe than the defect in pattern discrimination? As the 2 abilities were tested in different ways, it is not possible to give an unequivocal answer. To do so it would be necessary to examine thresholds for the discrimination of orientation, size, and shape in the mannner used for hue and with a range of stimuli of equal overall difficulty preoperatively. However, it is worth noting that group V4 performed poorly on postoperative retention with certain problems that the other groups found remarkably easy to discriminate, i.e., plus versus square and pairs of photographs of monkey faces, whereas they rapidly learned a simultaneous visual discrimination between 2 Munsell colors that were 6.25 steps apart in the red range (Table 2). We therefore conclude that their pattern discrimination deficit is at least as severe as their disturbance of hue discrimination and that it might be much more severe.

The change in hue discrimination thresholds in group V4 is of little interest if it is caused by inadvertent damage to the visual radiations and consequential field defects in foveal-macular vision. All 4 animals with ablation of V4 had retrograde degeneration in the dorsal lateral geniculate nuclei. The damage was slight in 2 animals but would have led to narrow sectorshaped defects along the horizontal meridian on one or both sides of the fovea in the other. However, the 2 animals with the greatest retrograde degeneration (V4-1 and V4-3) were respectively the least and the most impaired on pattern discriminations, suggesting that their similar field defects are not a major cause of poor perceptual discrimination. Conversely, the defect in hue discrimination was similar in all 4 animals in group V4, despite extensive variation in retrograde degeneration. Finally, and most importantly, the control animal with bilateral damage to the macular representation in striate cortex was unimpaired on either hue or pattern discrimination, despite having geniculate damage greater than that in every V4 animal.

Interest in the role of V4 in vision was especially stimulated by the reports that many more of its neurons were color selective than neurons in other visual areas (Zeki, 1973, 1977, 1978b) and that a substantial proportion are sensitive to perceived color (as judged by human observers) rather than to a narrow band of wavelengths (Zeki, 1980, 1983a, b). The latter observation is particularly interesting because it is tantamount to saying that a cell is capable of response invariance despite changes in the spectral composition of incident light, i.e., the cell shows color constancy. The first estimates of the proportion of cells in V4 that are tuned to wavelength were too high, probably because there is regional variation within V4 itself with respect to receptive field specialization (Zeki, 1977, 1978b, 1983c; Schein et al., 1982; Desimone et al., 1985). Many neurons in V4 are sensitive to orientation and to length rather than to wavelength or color, and if, as now seems likely, neurons of a particular physiological type are grouped in palches, it is easy to see how sampling artifacts can arise. According to Van Essen (1985), many V4 neurons are sensitive to retinal disparity, and as isoluminant-colored contours are notoriously poor stimuli for disparity mechanisms in human vision ( $\mathrm{Lu}$ and Fender, 1972; Gregory, 1979), these neurons too are presumably not specialized for dealing with wavelength. It now seems more likely that there is regional specialization within $\mathrm{V} 4$, just as there is within $\mathrm{V} 1$ and V2, and that the effects on both hue and form discrimination of removing V4 are compatible with this. For example, after staining for the mitochondrial enzyme cytochrome oxidase in striate cortex, there is a patchy distribution of densely labeled regions ("blobs") that are most conspicuous in layers 2 and 3 (Horton and Hubel, 1981; Horton, 1984). Cells within the blobs have nonoriented receptive fields and are double-opponent or broadband, whereas cells between the blobs have visual receptive fields that are oriented, whether or not they show singleopponent selectivity for color (Livingstone and Hubel, 1984). This modular organization is continued in V2. There, the thin cytochrome oxidase stripes are reciprocally connected to the blobs in V1, whereas the pale stripes (interstripes) in V2 are reciprocally connected to the interblob regions in $\mathrm{V} 1$. Within $\mathrm{V} 2$ the interconnections are chiefly between different thin stripes or different interstripes (Livingstone and Hubel, 1984), indicating that the segregation of different functional channels is maintained. There are also thick stripes rich in cytochrome oxidase in V2. Area V4 receives a projection from thin stripes in V2 that are rich in cytochrome oxidase (Shipp and Zeki, 1984, 1985a; DeYoe and Van Essen, 1985). As the neurons of V2 within the thin stripes are color opponent and not orientation selective, whereas those in pale stripes have the opposite characteristics (Shipp and Zeki, 1985a), there is good evidence that area V4 thereforc has conncctions and propertics compatible with a role in both pattern and color perception.

The sparing of achromatic discrimination thresholds after V4 lesions is also explicable in terms of recently established anatomical properties of V1, V2, and area MT (V5). Area MT receives a direct projection from layer $\mathrm{IVb}$ of $\mathrm{V} 1$, which also projects indirectly to $\mathrm{MT}$ via the thick cytochrome oxidase stripes of V2 (Shipp and Zeki, 1984, 1985b; DeYoe and Van Essen, 1985; see Van Essen, 1985, for review). As neurons in MT are indifferent to color (Zeki, 1983c; Van Essen, 1985), as are those in the thick cytochrome oxidase stripes of V2 (Hubel and Livingstone, 1985), and the geniculate input to layer IVb of V1 (via IV $\alpha$ ) arises from the broadband neurons in the magnocellular layers of $\mathrm{dLGN}$, our lesions have spared cortical projection systems carrying information about achromatic contrast.

The most intriguing property of neurons in V4 is that a substantial proportion are specific for color as opposed to wavelength. Would their removal lead to a defect in color constancy? The results we have reported on hue discrimination show that it will be difficult to test this, for an impairment in hue discrimination can hardly fail to affect color constancy. Only if the disturbance of color perception were much greater than that of wavelength discrimination could one be confident that they were independent. A disturbance of color constancy in 2 monkcys with V4 lesions was reported by Wild et al. (1985), but, as with our animals, one of them was impaired on postoperative retention of a range of tasks that included shapes, and both were inferior to 2 unoperated control animals on hue discrimination. The fact that the latter difference was not statistically significant is a necessary consequence of comparing groups that were too 
small for any group difference to be significant. Their impairment on the color constancy task is therefore difficult to interpret, especially as there was no evidence that the task was matched in difficulty with the hue-discrimination task. There is therefore still no clear evidence that color constancy is selectively disturbed by V4 lesions. Once again this is not surprising, given the absence of clinical reports of selective alterations in human color constancy despite well-documented examples of other disturbances in the perception of color (see below). Hue discrimination following V4 lesions in monkeys was examined by Dean (1979) using Munsell colors in the red/green range. No defects were found, but the lesions extended only slightly into the STS and only a millimeter or so into the lunate sulcus. A grossly subtotal lesion may be ineffective for the same reason that partial macular striate lesions were ineffective in the present study, as Dean himself recognized. It is also noteworthy that 2 of the four V4 animals in Dean's experiment had bilateral retrograde degeneration in the lateral geniculate nucleus "occupying a central band throughout its anterior posterior length." Although the degeneration was not illustrated, the description suggests that it was as severe as in the most affected of our animals and provides further evidence that impairments of hue discrimination following large V4 lesions are not a trivial consequence of field defects.

The color of an object, when part of a complex scene, is determined not only by the wavelength of light reflected from that object, but also depends on the spectral composition of the light from every point in the scene (Land, 1959). The neural basis of the predictive theories that explain the phenomenon of "color constancy" are poorly understood. It has been suggested (Livingston and Hubel, 1984) that the double-opponent cells in the blobs of striate cortex show properties consistent with the computations required by one such theory, the Retinex theory (Land, 1964, 1974, 1983). The Retinex model requires that the relative reflectances of the 3 cone channels be computed for each point of the visual scene. However, only 2 classes of doubleopponent cells (red/green and yellow/blue) have been observed in the cortical blobs, and these coexist with broadband cells that have the same spectral sensitivity throughout their receptive fields. The Retinex theory proposes that black, gray, or white are the result of the activation of the 3 cone channels and does not postulate the existence of a separate achromatic channel. Results of physiological recordings from single cortical neurons are clearly not consistent with this. A modified form of the theory has been proposed (Land, 1983) in which colors are represented on the 3 axes of red/green, blue/yellow, black/white rather than red, green, and blue. Recently, Desimone et al. (1985) have described cells in cortical area V4 that respond like a broadband color filter to light containing energy at many wavelengths. The excitatory receptive field center has a large suppressive surround where optimal inhibition occurs to light of the same wavelength that is stimulating the receptive field center and spatial interactions occur over large angular distances. Since these properties are consistent with the proposed "color filters" of Land (Land and McCann, 1971), it is possible that cortical area V4 plays a special role in color constancy but that this is not its only role.

The boundaries of V4 in the vicinity of the inferior occipital sulcus have never been thoroughly traced, and it is not clear whether V4 extends into area TEO, which is a small region between the inferior occipital sulcus and area TE (Bailey et al., 1950; Mishkin, 1972). What is clear is that removing area TEO sevcrcly disturbs pattern discrimination (Iwai and Mishkin, 1969) and that our V4 lesions involved parts of area TEO, especially in the 2 animals with the most severe impairment of pattern discrimination (V4-1 and -4). However, deliberately avoiding area TEO in an ablation experiment may be unwise until a proper study of its properties shows that it is not part of V4. In a study of the effects on vision of prestriate lesions, Cowey and Gross (1970) and Gross et al. (1971) made lesions that included the whole of area TEO and much of V4, but spared more of what is now known to be $\mathrm{V} 4$ in the lunate and superior temporal sulci. Although form discrimination was severely impaired, the animals were strikingly normal at discriminating between colored plaques. This could be yet another example of grossly incomplete removal of V4, but Gross et al. did not use isoluminant hues when testing color discrimination. The absence of any defect in discriminating colors following damage to V4 in this instance may therefore simply reflect the ability of other visual areas to code achromatic intensity differences. Neurons in V5 (also known as area MT) are indifferent to wavelength and to shape but are highly sensitive to achromatic borders (see van Essen, 1985, for review). As striate cortex projects directly to V5 and the latter has extensive forward connections with visual area in parietal and dorsal superior temporal cortex (Ungerleider, 1985; Ungerleider and Desimonc, 1986), the preservation of achromatic discrimination thresholds following removal of V4 may be a perceptual sign of parallel processing of visual information.

Selective disturbances in the response to colors following cortical damage in clinical patients are rare but well documented. In color anomia there is a disconnection between visual and language areas, leading to color-naming disorders that may (Geschwind and Fusillo, 1966) or may not (Oxbury et al., 1969) be associated with a disorder of object naming. In color dysphasia there is a disturbance in the language area itself, which can be selective for color words (Kinsbourne and Warrington 1964; Oxbury et al., 1969). In neither of these 2 conditions, nor in the condition of weakened short-term color memory described by Davidoff and Ostergaard (1984) is there any evidence that the ability to detect differences between isoluminant hues is disturbcd. However, the latter is grossy impaired in cerebral achromatopsia (see Meadows, 1974, for review), which therefore comes closest to resembling the effects of removing V4. Unfortunately, achromatic discrimination has been examined in only 2 achromatopsic patients. Both could discriminate small differences in gray much better than small differences in hue (Newcombe and Ratcliff, 1975; Heywood et al., 1986). Cerebral achromatopsia is also usually associated with object- and pattern-recognition disorders, as in our animals, but pattern discrimination and recognition can sometimes be normal (Damasio et al., 1980; Heywood et al., 1986). Finally, although the evolutionary development of the brain may explain why V4 is predominantly on the lateral surface of the hemisphere in monkeys, whereas the critical cortical damage in human cortical achromatopsia is ventromedial (Meadows, 1974; Damasio et al., 1980), the fact that the latter region consists of cytoarchitectonic area 37 whereas $\mathrm{V} 4$ is in area 18 suggests that removing V4 may not provide a model of cerebral achromatopsia.

The operated control group in the present experiment received unilateral or bilateral removal of the cortex in the STS, where up to $20 \%$ of the neurons show response selectivity for faces or parts of faces (Baylis et al., 1985; see Rolls, 1984, for review). Although the animals were mildly impaired on postoperative 
retention of the first of 4 simultaneous discriminations between photographs of monkey faces, there was no indication of a selective and severe disturbance of facial discrimination. They therefore do not resemble patients with apperceptive visual agnosia for complex visual patterns such as faces. However, they could well be impaired on facial recognition or at perceiving facial characteristics such as angle of regard, to which many of the neurons are also sensitive. These possibilities are being tested now.

\section{References}

Bailey, P., G. v. Bonin, and W. S. McCulloch (1950) The Isocortex of the Chimpanzee, University of Illinois Press, Urbana, IL.

Baylis, G. C., E. T. Rolls, and C. M. Leonard (1985) Selectivity between faces in the responses of a population of neurons in the cortex in the superior temporal sulcus of the monkey. Brain Res. 342: 91102.

Bellamy, B. R., and S. M. Newhall (1942) Attributive limens in selected regions of the Munsell Color solid. J. Opt. Soc. Am. 32: 465473.

Cowey, A., and C. G. Gross (1970) Effects of foveal prestriate and inferotemporal lesions on visual discrimination by rhesus monkeys. Exp. Brain Res. 11: 128-144.

Cragg, B. G., and A. Ainsworth (1969) The topography of the afferent projections in the circumstriate visual cortex of the monkey studied by the Nauta method. Vis. Kes. 9: 733-747.

Damasio, A., T. Yamada, H. Damasio, J. Corbett, and J. McKee (1980) Central achromatopsia: Behavioral, anatomic, and physiologic aspects. Neurology 30: 1064-1071.

Daniel, P. M., and D. Whitteridge (1961) The representation of the visual field on the cerebral cortex in monkeys. J. Physiol. (I ondon) 159: 203-221.

Davidoff, J. B., and A. L. Ostergaard (1984) Colour anomia resulting from weakened short-term colour memory. Brain 107: 415-431.

Dean, P. (1979) Visual cortex ablation and thresholds for successively presented stimuli in rhesus monkeys: II. Hue. Exp. Brain Res. 35: 69-83.

Desimone, R., S. J. Schein, J. Moran, and L. G. Ungerleider (1985) Contour, color and shape analysis beyond the striate cortex. Vis. Res. 25: 441-452.

DeYoe, E. A., and D. C. Van Essen (1985) Segregation of efferent connections and receptive field properties in visual area V2 of the macaque. Nature 317: 58-61.

French, G. M. (1965) Associative problems. In Behavior of Non-human Primates. A. M. Schrier, H. F. Harlow, and F. Stollnitz, eds., Volume 1, pp. 167-209, Academic, New York.

Gallyas, F. (1979) Silver staining of myelin by means of physical development. Neurol. Res. 1: 203-209.

Geschwind, N., and M. Fusillo (1966) Color-naming deficits in association with alexia. Arch. Neurol. (Chicago) 15: 137-146.

Granville, W. C., D. Nickerson, and C. E. Foss (1943) Trichromatic specifications for intermediate and special colors of the Munsell system. J. Opt. Soc. Am. 33: 365-385.

Gregory, R. L. (1979) Stereo vision and isoluminance. Proc. R. Soc. London [Biol.] 204: 467-476.

Gross, C. G., A. Cowey, and F. J. Manning (1971) Further analysis of visual discrimination deficits following foveal prestriate and inferotemporal lesions in rhesus monkeys. J. Comp. Physiol. Psychol. 76: $1-7$.

Heywood, C. A., B. Wilson, and A. Cowey (1987) A case study of cortical colour 'blindness' with relatively intact achromatic discrimination. J. Neurol. Neurosurg. Psychiatr. 50: 22-29.

Horton, J. C. (1984) Cytochrome oxidase patches: A new cytoarchitechtonic feature of monkey visual cortex. Phil. Trans. R. Soc. London B304: 199-253.

Horton, J. C., and D. H. Hubel (1981) A regular patchy distribution of cytochrome-oxidase staining in primary visual cortex of the macaque monkey. Nature 292: 762-764.

Hubel, D. H., and M. S. Livingstone (1985) Complex-unoriented cells in a subregion of primate area 18. Nature $315: 325-327$.

Iwai, E., and M. Mishkin (1969) Further evidence on the locus of the visual area in the temporal lobe of the monkey. Exp. Neurol. 25: 585594.

Kelly, K. L., K. S. Gibson, and D. Nickerson (1943) Tristimulus specification of the Munsell Book of Color from spectrophotometric measurements. J. Opt. Soc. Am. 33: 355-376.

Kinsbourne, M., and F. K. Warrington (1964) Observations on colour anomia. J. Neurol. Neurosurg. Psychiatr. 27: 296-299.

Land, E. H. (1959) Color vision and the natural image. Part 1. Proc. Natl. $\Lambda$ cad. Sci. USA 45: 115-129.

Land, E. H. (1964) The Retinex. Am. Sci. 52: 247-264.

Land, E. H. (1974) The Retinex theory of color vision. Proc. R. Inst. Gr. Brit. 47: 23-58.

Land, E. H. (1983) Color vision and the natural image. III. Recent advances in Retinex theory and some implications for cortical computations. Proc. Natl. Acad. Sci. USA 80: 5163-5169.

Land, E. H., and J. J. McCann (1971) Lightness and Retinex theory. J. Opt. Soc. Am. 172: 1-11.

Livingstone, M. S., and D. H. Hubel (1984) Anatomy and physiology of a color system in the primate visual cortex. J. Neurosci. 4: 309356.

Lu, C., and D. H. Fender (1972) The interaction of colour and luminance in stereoscopic vision. Invest. Ophthalmol. 2: 482-489.

Maunsell, J. H. R., and D. C. Van Essen (1983) The connections of the middle temporal area (MT) and their relationship to a cortical hierarchy in the macaque monkey. J. Neurosci. 3: 2563-2586.

Mishkin, M. (1972) Cortical visual areas and their interaction. In Brain and Human Behavior, A. G. Karczmar and J. C. Eccles, eds., pp. 187-208, Springer-Verlag, Berlin.

Meadows, J. C. (1974) Disturbed perception of colours associated with localized cerebral lesions. Brain 97: 615-632.

Moon, L. E., and H. F. Harlow (1955) Analysis of oddity learning by rhesus monkeys. J. Comp. Physiol. Psychol. 48: 188-194.

Newcombe, F., and G. Ratcliff (1975) In Les Syndromes de Disconnexion Calleuse chez l'Homme, F. Michel and B. Schott, eds., pp. 317-341 (Colloque International de Lyon 1974), Hôpital Neurologique de Lyon.

Newhall, S. M., D. Nickerson, and D. B. Judd (1943) Final report of the O.S.A. subcommittee on the spacing of the Munsell colors. J. Opt. Soc. Am. 33: 385-418.

Oxbury, J. M., S. M. Oxbury, and N. D. Humphrey (1969) Varieties of colour anomia. Brain 92: 847-860.

Robinson, E. W. (1933) A preliminary experiment on abstraction in a monkey. J. Comp. Psychol. 16:231-236.

Rolls, E. T. (1984) Neurons in the cortex of the temporal lobe and in the amygdala of the monkey with responses selective for faces. Hum. Neurobiol. 3: 209-222.

Schein, S. J, R. T. Marrocco, and F. M. De Monasterio (1982) Is there a high concentration of color-selective cells in area V4 of monkey visual cortex? J. Neurophysiol, 47: 193-213.

Shipp, S. D., and S. Zeki (1984) Specificity of connexions is related to cytochrome oxidase architecture in area V2 of macaque monkey. J. Physiol. (Lond.) 353: 23P.

Shipp, S. D., and S. Zeki (1985a) Segregation of pathways leading from area V 2 to areas V4 and V 5 of macaque monkey visual cortex. Nature 315: 322-325.

Shipp, S. D., and S. Zeki (1985b) Segregated output to area V5 from layer 4B of macaque monkey striate cortex. J. Physiol. (Lond.) 369 : $32 \mathrm{P}$.

Talbot, S. A., and W. M. Marshall (1941) Physiological studies on neuronal mechanisms of visual localization and discrimination. Am. J. Ophthalmol. 24: 1255-1264.

Ungerleider, L. G. (1985) The corticocortical pathways for object recognition and spatial perception. In Pattern Recognition Mechanisms, Vol. 54, C. Chagas, R. Gattas, and C. Gross, eds., pp. 21-39, Pontificiae Academiae Scientiarum Scripta Varia., Vatican City, Italy.

Ungerleider, L. G., and R. Desimone (1986) Cortical connections of visual area MT in the macaque. J. Comp. Neurol. 248: 190-222.

Ungerleider, L. G., and M. Mishkin (1982) Two cortical visual systems. In Analysis of Visual Behavior, D. J. Ingle, M. A. Goodale, and R. J. W. Mansfield, eds., pp. 549-586. MIT Press, Cambridge, MA.

Van Essen, D. C. (1985) Functional organization of primate visual cortex. In Cerebral Cortex, Vol. 3, A. Peters and E. G. Jones, eds., pp. 259-329, Plenum, New York.

Weller, R. E., and J. H. Kaas (1983) Retinotopic patterns of connec- 
tions of area 17 with visual areas V-II and MT in macaque monkeys. J. Comp. Neurol. 220: 253-279.

Wild, H. M., S. R. Butler, D. Carden, and J. J. Kulikowski (1985) Primate cortical area V4 important for colour constancy but not wavelength discrimination. Nature 313: 133-135.

Zeki, S. M. (1969) Representation of central visual fields in prestriate cortex of monkey. Brain Res. 14: 271-291.

Zeki, S. M. (1971) Cortical projections from two prestriate areas in the monkey. Brain Res. 34: 19-35.

Zeki, S. M. (1973) Colour coding in rhesus monkey prestriate cortex. Brain Res. 53: 422-427.

Zeki, S. M. (1977) Colour coding in the superior temporal sulcus of the rhesus monkey visual cortex. Proc. R. Soc. London 274: 195223.

Zeki, S. M. (1978a) Uniformity and diversity of structure and function in rhesus monkey prestriate visual cortex. J. Physiol. (Lond.) 277: 273-290.
Zeki, S. M. (1978b) Functional specialization in the visual cortex of the rhesus monkey. Nature 274: 423-428.

Zeki, S. M. (1980) The representation of colours in the cerebral cortex. Nature $284: 412$.

Zeki, S. M. (1983a) Colour coding in the cerebral cortex: The reaction of cells in monkey visual cortex to wavelengths and colours. Neuroscience $9: 741-765$.

Zeki, S. M. (1983b) Colour coding in the cerebral cortex: The response of wavelength-selective and colour coded cells in monkey visual cortex to changes in wavelength composition. Neuroscience 9: 767-781.

Zeki, S. M. (1983c) The distribution of wavelength and orientation cells in different areas of monkey visual cortex. Proc. R. Soc. London [Biol.] 217: 449-470.

Zihl, J., D. von Cramon, and N. Mai (1983) Selective disturbance of movement vision after bilateral brain damage. Brain 106: 313-340. 